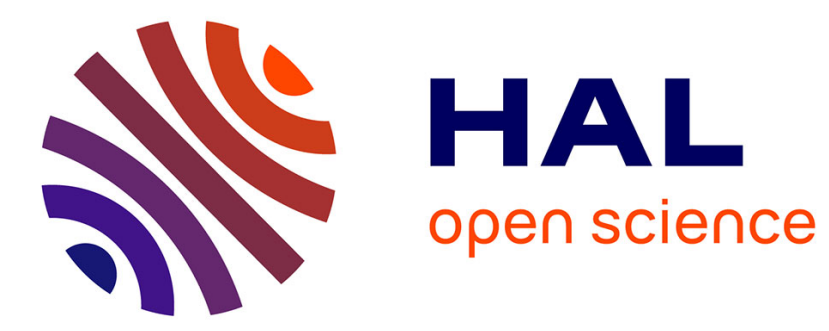

\title{
Recent rheologic processes on dark polar dunes of Mars: Driven by interfacial water?
}

\author{
A. Null Kereszturi, D. Möhlmann, Sz. Berczi, T. Ganti, A. Kuti, A. Sik, A. \\ Horvath
}

\section{- To cite this version:}

A. Null Kereszturi, D. Möhlmann, Sz. Berczi, T. Ganti, A. Kuti, et al.. Recent rheologic processes on dark polar dunes of Mars: Driven by interfacial water?. Icarus, 2009, 201 (2), pp.492. 10.1016/j.icarus.2009.01.014 . hal-00533499

\section{HAL Id: hal-00533499 \\ https://hal.science/hal-00533499}

Submitted on 7 Nov 2010

HAL is a multi-disciplinary open access archive for the deposit and dissemination of scientific research documents, whether they are published or not. The documents may come from teaching and research institutions in France or abroad, or from public or private research centers.
L'archive ouverte pluridisciplinaire HAL, est destinée au dépôt et à la diffusion de documents scientifiques de niveau recherche, publiés ou non, émanant des établissements d'enseignement et de recherche français ou étrangers, des laboratoires publics ou privés. 


\section{Accepted Manuscript}

Recent rheologic processes on dark polar dunes of Mars: Driven by interfacial water?

A. Kereszturi, D. Möhlmann, Sz. Berczi, T. Ganti, A. Kuti, A. Sik, A. Horvath

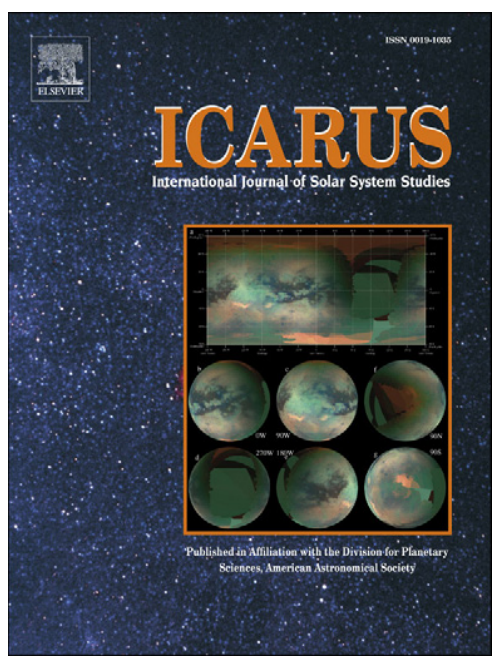

PII: $\quad$ S0019-1035(09)00035-9

DOI: $\quad$ 10.1016/j.icarus.2009.01.014

Reference: $\quad$ YICAR 8895

To appear in: Icarus

Received date: 16 September 2008

Revised date: 27 January 2009

Accepted date: 27 January 2009

Please cite this article as: A. Kereszturi, D. Möhlmann, Sz. Berczi, T. Ganti, A. Kuti, A. Sik, A. Horvath, Recent rheologic processes on dark polar dunes of Mars: Driven by interfacial water?, Icarus (2009), doi: 10.1016/j.icarus.2009.01.014

This is a PDF file of an unedited manuscript that has been accepted for publication. As a service to our customers we are providing this early version of the manuscript. The manuscript will undergo copyediting, typesetting, and review of the resulting proof before it is published in its final form. Please note that during the production process errors may be discovered which could affect the content, and all legal disclaimers that apply to the journal pertain. 
$1 \quad$ Recent rheologic processes on dark polar dunes of Mars: Driven by interfacial water?

2

3 A. Kereszturi ${ }^{1,7,8}$,D. Möhlmann ${ }^{2}$, Sz. Berczi ${ }^{1,3}$, T. Ganti ${ }^{1}$, A. Kuti ${ }^{5,7}$, A. Sik ${ }^{1,4}$, A. Horvath ${ }^{1,6}$

4

$5{ }^{1}$ Collegium Budapest, Institute for Advanced Study, H-1041 Budapest, Szentharomsag 2. Hungary

72 DLR Institut für Planetenforschung, D-12489 Berlin, Rutherfordstr. 2. Germany,

$8{ }^{3}$ Eotvos Lorand University of Sciences, Institute of Physics, H-1117 Budapest Pázmány 1/A.

9

$10{ }^{4}$ Eotvos Lorand University of Sciences, Institute of Geography and Earth Sciences, H-1117 11

$12{ }^{5}$ Eotvos Lorand University of Sciences, Institute of Physics, Department of Astronomy, H-
1117 Budapest Pázmány 1/c. Hungary

${ }^{6}$ Konkoly Observatory, H-1525 Budapest Pf. 67. Hungary

${ }^{7}$ Hungarian Astronomical Association, H-1461 Budapest, Pf. 219. Hungary

${ }^{8}$ Károly Nagy Astronomical Foundation, H-1011 Budapest, Szekely u. 2-4., Hungary 
18

19 Editorial correspondence to:

20 dr. Akos Kereszturi,

21 Collegium Budapest Institute for Advanced Study, H-1041 Budapest, Szentharomsag 2.

22 Hungary

23 E-mail address: akos@colbud.hu 


\section{Abstract}

25

26

27

28

29

In springtime on HiRISE images of the Southern polar terrain of Mars flow-like or rheologic features were observed. Their dark color is interpreted as partly defrosted surface where the temperature is too high for $\mathrm{CO}_{2}$ but low enough for $\mathrm{H}_{2} \mathrm{O}$ ice to be present there. These branching stripes grow in size and can move by an average velocity of up to about $1 \mathrm{~m} /$ day and could terminate in pond-like accumulation features. The phenomenon may be the result of interfacial water driven rheologic processes.

Liquid interfacial water can in the presence of water ice exist well below the melting point of bulk water, by melting in course of interfacial attractive pressure by intermolecular forces (van der Waals forces e.g.), curvature of water film surfaces, and e.g. by macroscopic weight, acting upon ice. This melting phenomenon can be described in terms of "premelting of ice". It is a challenging consequence, that liquid interfacial water unavoidably must in form of nanometric layers be present in water ice containing soil in the subsurface of Mars. It is the aim of this paper to study possible rheologic consequences in relation to observations, which seem to happen at sites of "dark dunes" on Mars at present.

The model in this work assumes that interfacial water accumulates at the bottom of a translucent water-ice layer above a dark and insolated ground. This is warmed up towards the melting point of water. The evolving layer of liquid interfacial water between the covering ice sheet and the heated ground is assumed to drive downward directed flow-like features on slopes, and it can, at least partially, infiltrate (seep) into a porous ground. There, in at least temporarily cooler subsurface layers, the infiltrated liquid water refreezes and forms ice. The related stress built-up is shown to be sufficient to cause destructive erosive processes. The above-mentioned processes may cause change in the structure and thickness of the covering 
50 ice and/or may cause the movement of dune grains. All these processes may explain the

51 observed springtime growing and downward extension of the slope streaks analyzed here.

52

53 Keywords: Mars, surface; ices; water, subsurface 


\section{Introduction}

56

57 Bulk water cannot stably exist at the thermodynamic conditions in a broad range of subzerotemperatures present on Mars. However, liquid interfacial water must stably exist at these temperatures also in the subsurface of Mars if the soil contains ice (Möhlmann 2004) and ice must be present in the uppermost surface due to adsorption and freezing of atmospheric water vapour, and/or the ice may also be a subsurface relict of earlier water rich Martian epochs. Salts may influence the upper situation.

Liquid interfacial water in the $\mathrm{H}_{2} \mathrm{O}$-ice containing parts of the subsurface of Mars today may be related to physical, chemical, and eventually also to biological processes (Möhlmann 2008). The presence of this interfacial water may be enhanced and extended to lower temperatures in brines of various salts (Mellon and Phillips, 2001; Knauth and Burt 2002) and may help destabilizing slope materials (Kossacki and Markiewitz 2008). Brass (1980) analysed the freezing point of various salt-water systems on Mars and suggested freezing point may be as low as $225 \mathrm{~K}$. Interesting analogues have been discovered in the Antarctica Dry Valleys with some liquid water related structures, resembling to Martian low latitude slope streaks (Head et al. 2007a, Head et al. 2007b).

\section{Types of ices and frost in the analyzed terrains}

It is important to distinguish between the two kinds of ice covering the Martian surface: carbon dioxide ice and water ice. The structure of these ice types (slab or porous) is not well known, however it is possible to distinguish between the water and carbon dioxide ices on the basis of their spectra, albedo and related surface temperature together. In this work, we 
analyzed terrains by using satellite-born images, and TES albedo- and temperature values. In every case we have indicated, which type of ice is probably on the surface, and which parameters suggest the presence of that one, and the absence of the other kind of ice.

Hereafter first we present the observations and description of polar springtime surface features, where springtime insolation gives rise to strange features resembling to those caused by a flowing liquid. In the second part, a theoretical and modeling background to describe these recent rheological phenomena is given, which is based on the at least temporary presence of interfacial water in the uppermost surface layers. Detailed information about the formation of this interfacial and adsorbed water layer on the soil grains can be found in the references, here we only present some basic formulas in connection with the observed structures.

The frost cover and its sublimation play an important role in the interpretation of our observations. Both water and carbon dioxide ice can be present on the Martian surface inside the seasonal caps. At the Northern Polar Region water ice forms a wide annulus at the perimeter of the receding seasonal carbon dioxide ice cover (Kieffer and Titus 2001, Bibring et al. 2005, Schmitt et al. 2005, Schmitt et al. 2006), partly because it appears from below the sublimated carbon dioxide seasonal cap and partly because it recondenses onto the perimeter of the remaining carbon dioxide ice (Wagstaff et al. 2008). Opposite to this situation at north, no similar water ice annulus was observed at the Southern Polar Region, only smaller water ice patches (Titus 2005, Langevin et al. 2006, Titus 2008) are present, which appear at the perimeter of the receding annular carbon dioxide cap, and somewhere they are tens of kilometers away from the bright permanent cap (Bibring et al. 2004) in summertime. 
105 These observations can be interpreted, by assuming that a thin water ice layer below the

106 seasonal carbon dioxide frost is present, and water ice is left behind the sublimating carbon

107 dioxide ice cover. Such stratigraphy can be expected from theoretical reasons, too: when

108 seasonal cooling starts, ice condenses on the surface first from the cooling atmospheric water

109 vapor, and carbon dioxide (by its lower frost temperature) condenses later, forming a layered

110 structure. At the landing site of the Phoenix probe also water ice frost appeared first with the

111 cooling temperature in autumn (Lunar and Planetary Laboratory Press Release) as it was too

112 warm there to see any dry ice. This frost probably formed by direct condensation from the

113 atmosphere, although falling snowflakes were also observed by LIDAR on Phoenix (NASA

114 Press Release 2008).

115

116 The mentioned above observations and theoretical assumptions suggest that at polar terrains

117 on Mars, when the temperature is above the carbon dioxide frost point, and as long as the

118 surface is still frost covered, this frost is water ice.

119

120

\section{Appearance of the possible seepage features}

122 We observed dark slope structures emanating from Dark Dune Spots (DDSs) in the southern

123 terrain on MGS MOC (Horvath et al. 2001), and MRO HiRISE images. DDSs are a special

124 class of polar seasonal albedo features, their basic characteristics are the following: they are

125 round shaped low albedo structures on the seasonal frost-covered surface of dark dunes,

126 appear late winter, grow in size and number, and finally disappear with the disappearance of

127 seasonal frost in early summer. They are present in the Southern hemisphere between $65-80$

128 degrees of latitude. (Although resembling seasonal dark albedo structures are present in the

129 northern hemisphere too, they are excluded this.) 
131 The most important features related to DDSs are the elongated slope streaks (Horváth et al.

132 2001, Gánti et al. 2003, Szathmary et al. 2005). These slope structures always start from these 133 spots, at the analyzed terrain. These spots form special groups among the various ephemeral 134 seasonal albedo structures on Mars observed by different authors (Christensen et al. 2005;

135 Kieffer, 2003; Malin and Edgett, 2000; Piqueux et al. 2003).

137 DDSs generally show internal structures with a darker (umbra-like) central part, surrounded 138 by a lighter, outer (penumbra-like) ring - although there are many irregular shaped spots among them. Their diameters vary between 5 and $200 \mathrm{~m}$; and have a yearly reoccurrence to a degree of $50-65 \%$, meaning that about half of the spots appear very close (in meter scale

141 distance) to the location of spots from the previous year. Their most interesting aspect 142 analyzed in this work is the elongated structures on slopes, emanating from them.

144 Dark Dune Spots were analyzed previously on MGS MOC images (Horváth et al. 2001, Gánti 145 et al. 2003, Gánti et al. 2006, Kereszturi et al. 2007, Szathmary et al. 2007). Based on the comparison of morphology, location and seasonal appearance of seasonal dark spots on new

147 HiRISE and earlier MOC images, we suggest the dark spots and slope structures observed in 148 the HiRISE images represent the same phenomena as earlier noted on MOC images (Fig. 1.).

150 The streaks emanating from these spots, form two groups. The larger group consists of 151 diffuse, fan shaped streaks, probably formed by the combination of $\mathrm{CO}_{2}$ geyser activity and winds (Kieffer et al. 2006) on slopes and horizontal terrains too. The second group has a confined appearance (we call them confined streaks hereafter), which evolves during a later seasonal phase. These are seen only on slopes (Kereszturi et al. 2007, 2008), when the surface temperature is sufficiently high, and consequently less or no $\mathrm{CO}_{2}$ ice cover is present. 
157 The temperature values during this later seasonal phase are too high for the carbon dioxide ice

158 to cover the whole observed area. Unfortunately the spatial resolution of TES temperature

159 data is not high enough to observe precisely the area of these dark structures, so we cannot

160 determine are they free of $\mathrm{CO}_{2}$ ice, but it is highly probable. If the temperature of a kilometer

161 sized terrain is higher than the $\mathrm{CO}_{2}$ frost point, then $\mathrm{CO}_{2}$ frost free areas can be expected to

162 exist. The mentioned above dark features must absorb more sunlight than their surroundings,

163 so they must be warmer than the average temperature of the observed area. Because of this

164 and the earlier observations of stratigraphic relationship of $\mathrm{H}_{2} \mathrm{O}$ ice below $\mathrm{CO}_{2}$ ice (see

165 section 2), it is possible that $\mathrm{CO} 2$ ice is absent in the spots, and water ice left behind because

166 of the above mentioned layered structure.

167

168 On the analyzed HiRISE images both of the upper mentioned two slope streak groups, the

169 diffuse and the confined were also identified, as well on MOC images. On HiRISE images the

170 diffuse streaks turned out to consist of small $(0,2-2 \mathrm{~m})$ dark patches that form a discontinuous

171 fan-shaped structure. These small patches were visible as coalesced, continuous diffuse fans

172 in the lower resolution images of MGS MOC. The confined streaks, seen already on MGS

173 MOC images, look like continuous dark streaks on HiRISE images too.

$175 \quad$ 4. Method of slope streak analysis

177 For the analysis we used HiRISE (MRO), HRSC (MEX), MOC (MGS) images, with 178 topographic data from MGS MOLA PEDR (Precision Experiment Data Record) dataset with 179 processing version L (Smith D. et al. 1999), and temperature data from TES (MGS) 180 measurements (Christensen 1992), using the "vanilla" software. Temperature data show 181 annual trend, and were derived for daytime around $2 \mathrm{pm}$, local true solar time. The surface 182 temperature values have spatial resolution of around $3 \mathrm{~km}$, so they can be taken only as a 
183

184

rough approach of the surface temperature of the whole analyzed dune complex. Another source of uncertainty is that the temperature values were used only to realize a general annual trend. These values can be taken as an orienting approach only to the conditions at the observed locations and dates.

The change of seasonal albedo structures was analyzed on dunes inside three craters during southern spring: Russel (54S 12E), an unnamed crater (68S 2E), and Richardson (72S 180E). Only 11 of the analyzed HiRISE images of these craters showed confined slope streaks. Their parameters can be seen in Table 1 .

For temperature analysis we used MGS TES bolometer data, acquired in nadir-pointing mode with "vanilla" software. Other data on Martian surface temperatures could be acquired form THMEIS too, that has better spatial resolution but unfortunately observed rarely the same terrain.

During the analysis we used the following terms to characterize the structures. The term "slope streak" is used here only for those structures, which are analyzed in this paper, although in the literature it is generally used for low latitude streaks formed possibly by the mass wasting process of dust (Aharonson et al. 2003, Schorghofer et al. 2007, Beyer et al. 2008, Chuang et al. 2007). Here it is used for elongated structures that stretch in downward direction on slopes, and emanate from DDSs. The term "movement" was used here for the description of the change in the location of dark colored surface parts, and that probably, but not necessarily means the real movement of any material. Theoretically changes in phase or color at neighboring locations can also manifest in a similar phenomenon. We used the term "flow front" for the advancing frontal section of these elongated dark slope structures, toward 
208 the direction of their movement. Rheologic term is also used for the movement of material on

209 the surface or right below it.

210

211 5. Morphology of slope structures

212

213 The structures analyzed in this article were observed on dark dunes inside craters at the

214 southern hemisphere. These dunes are actually complexes of smaller dune units with size of

215 around $1 \mathrm{~km}$, and the diameter of one complex is between $10 \mathrm{~km}$ and $20 \mathrm{~km}$. The smallest

216 visible topographic structures are ripples on the top of the upper mentioned structures, with

217 width of $5 \mathrm{~m}-20 \mathrm{~m}$. During the observations the surface was covered with bright frost (at the

218 beginning $\mathrm{CO}_{2}$, later possibly somewhere only $\mathrm{H}_{2} \mathrm{O}$ ), peppered with small Dark Dune Spots

219 and the slope features emanated from them. Analyzing nearly one hundred slope streaks on

220 HiRISE images, a characteristic sequence of events is visible that follows each other as the

221 season passes by. The phases of the DDS and related slope streak changes are:

222

223

224

225

226

227

228

229

1. A dark spot appears, at some occasions with fan shaped streaks emanating from it (it can not be decided whether the spot appears first before the fan, or they appear at the same time).

2. Confined streaks start emanate from DDSs in downward direction at slopes.

3. The branching pattern of the streaks becomes more developed and the streaks become longer as time passes by. During this phase a brighter halo comes visible around both the DDS and the slope streak, possibly related to some refreezing phenomenon.

230

4. With the advancement of seasons (towards summer) the dark parts become gray and gradually reach the dark color of the whole dune complex. 
5. The color/brightness of the whole terrain gets more and more homogeneous, and finally only small signs of the previously observed dark albedo markings remain visible.

In the second and third phases of the mentioned above sequence, slope streaks are obviously present as dark features elongated downward on the slopes. For the determination of the downward direction, we can use MOLA topography only in the cases of the largest slopes. In most of the cases, the slope direction was identified on the basis of the lighting condition, where the sunward slopes were generally brighter than the opposite ones (see Fig. 2. for examples, where the Sun illuminates from the right, so the brighter slopes are tilted toward the right). Slope streaks were observed only at those locations where the sloping angle was high enough to produce obvious brightness differences between opposite slopes. Based on the analysis of some individual MOLA measurements, the slope angle was somewhere between 5 and 20 degrees (here the horizontal plane has 0 , the vertical 90 degree of slope angle).

The confined slope streaks always follow the sloping direction, regardless to the exposure of the slope faces (e.g. north, south, east, west). No such preferred direction is visible among the differently oriented slopes, although it is worth noting that homogeneous samples may hardly exist because the dune crests in many cases are north-south oriented, probably by the general east-west winds. This suggests that the slope angle value plays stronger role, than orientation of the slope.

All the confined slope streaks visible in the mentioned above images emanate from the Dark Dune Spots in downslope direction. They have characteristic appearance: forming a branching network, where the smallest branch had a width of $3-6 \mathrm{~m}$. This latter may be a characteristic value, and it is equal to the average distance between the small dune ripples, which influence 
their path like "channeling". At many locations individual branches split into two branches

259 because of obstacle-forming ripples, and there are also cases where two or more branches 260 coalesce.

261

262

\section{Movement of slope streaks}

264 We use the term of movement for the downward stretch of the dark slope streaks emanate

265 from Dark Dune Spots as time passes by. Regarding the movement of the low albedo slope 266 streaks, we have observed the following:

267

- The dark slope streaks always start from the DDSs downward, regardless the fact, is the DDS situated at the dune crest or on the slope itself - although more DDSs are present at the top of a slope than on the slope. No streaks are visible without DDSs (except for those cases where the DDS, that probably triggered the streak formation, diminishes during the streak movement, possibly by some refreezing phenomenon). This means that the processes, which trigger the formation of slope streaks are in connection with DDSs. The reason for these processes may be related to the dark color of the DDS that supports an increase of the temperature. shaped streaks in various directions.

- The dark colored slope streaks become longer as time passes by in many cases - while

- All the confined streaks stretch downward on slopes, suggesting that gravity driven effects dominate the development, opposite to the gas jet process, which forms fan there were slope streaks, which did not grow during the same period, and did not show any movement. In an earlier work (Horvath et al. 2008) we have shown that there is a statistical connection between the length of a slope structure and the size of the 
original DDS that may be valid here as well - although the situation seems to be more complicated for slope streaks.

- The advancing flow front follows the several meter sized furrow-like depressions between the small, probably wind-blown ripples.

- During the late phase of the dark material's movement, sometimes the source region

Based on the analysis of morphology and its changes in time, we have identified two subgroups of confined streaks, emanating from dune spots: active and passive streaks (Fig.

3.). We use the term "active confined streak" for such streaks, which show evident signs of gradual movement of dark fronts as the season passes by (Fig. 4.). In the case of "inactive confined streaks", no similar moving flow front was observable, and only the small and separated dark parts became visible as the season passed by. With the progress of the spring 
309

310

311

313

314

end of this coalescence, the passive streak gains similar appearance to an active confined streak. The elongated morphology suggests that these streaks have already moved in the past, possibly during different climatic periods, but currently they only show a locally fixed darkening without movement.

We have measured the movement speed of the flow fronts of active streaks for several individual branches on subsequent images, where the same branch of certain slope streaks could be firmly identified. The measured values were calculated for Martian days (sols) as an average value, as if the whole movement had happened during a full Martian sol. If the theory described in this paper can be applied, a thin liquid film of interfacial water lubricates the grains. The resulting movement may take place only during a small part of a Martian day, probably when the temperature and water content produce a sufficiently thick layer of undercooled liquid interfacial water. Also freezing may cause expansion and failure inside the dunes' structure (see in section 8.3).

The observed average motion speed of flow fronts has been estimated to be of up to $1.4 \mathrm{~m} / \mathrm{sol}$. There were many occasions where the dark stuff did not move, or moved slower than 0.1 $\mathrm{m} / \mathrm{sol}$. Where the movement was obvious, it usually happened on meter scale distance on the average on a Martian day (Fig. 5.). This suggests the presence of some critical limit above which the movement took place, and that it happens at a reasonable distance.

\section{Connection between temperature and morphology}

We have analyzed average annual TES based surface temperatures and the related morphology of the slope streaks. The three observed craters were situated at different latitude, at $54 \mathrm{~S}, 68 \mathrm{~S}$ and $72 \mathrm{~S}$. As a result, during the springtime warming the average surface 
335

336

337

338

339

340

341

342

343

344

345

346

347

348

349

350

351

352

353

354

355

356

357

358

359

temperature reaches certain values later in solar longitude for locations farther from the equator. If the beginning of the dark streaks' movement takes place after the temperature has reached a critical value, it is expected that the movement starts later closer to the south pole.

We have studied the annual temperatures (Fig. 6., 7., 8.), with continuous TES based datasets, but regarding the images unfortunately there is no continuous coverage of the whole spring period available. The first indications of streak movement can be observed earlier in Richardson crater than in Russel crater, because for Russel no image is available for the critical period. So, it was not yet possible to establish a direct relation between the first appearance of streaks and the seasonal increase in temperatures.

The TES temperature values can be taken only as a rough approach for the surface temperatures. Because of the comparatively low spatial resolution of the detector, it cannot resolve certain parts of the dark features, which may be warmer than the measured "average" value. In spite of this restriction, the streaks' movement started around the same temperature in Russel, the unnamed crater, and probably in Richardson crater too, but there the situation is somewhat different, as described below in more in detail.

Analyzing the average annual temperature trend and the changes in streaks' morphology, the streaks appeared in Russel and the unnamed crater when the temperature was between $180 \mathrm{~K}$ and $200 \mathrm{~K}$. In Richardson crater the situation is different: the first indication of the slope streak movement there appeared on the images acquired at $\mathrm{Ls}=210.6$, when the average temperature is not much above the frost point of carbon dioxide. But the temperature curve has already started to rise, suggesting that there must be warmer locations free of $\mathrm{CO}_{2}$ frost on the surface, but they are probably below the limit of the spatial resolution. These warmer 
360

361

362

363

364

365

366

367

368

369

370

371

372

373

374

375

376

377

378

379

380

381

382

383

384

385

small patches may be the dark features, because their much lower albedo causes a warm-up in course of the increasing insolation.

In general, and based on TES temperature data, it can be stated that during the movement of slope structures, a large part of the surface (or the whole observed area) is free of carbon dioxide ice, as the temperature of the dark slopes is above the $\mathrm{CO}_{2}$ freezing point. At the same time, based on the images, frost covers most of the terrains, so that frost is probably composed of water ice. As a conclusion the dark slope streaks are active during a seasonal phase when water ice is probably present and exposed to the surface in the analyzed regions.

Because of the small number of available HiRISE images of the slope movement phenomena and the lack of continuous data sets, the exact determination of the appearance / disappearance of slope structures is not yet possible. But several important conclusions can already be drawn from the available images. Based on the comparison of images and temperature data from different latitudes, the flow-like (or rheologic) process seems to start when the temperature is above the carbon dioxide frost point, around about $180-200 \mathrm{~K}$. The movements usually take place on a meter scale distance per day. The phenomenon of an undercooled liquid interfacial water layer may help to understand these movements on slopes, as described below.

\section{Liquid interfacial water on Mars}

Around hydrophilic mineral grains embedded in snow/ice, a layer of liquid interfacial water must form between the mineral surface and the snow/ice (Möhlmann, 2008). The reason is the freezing point depression due to the attractive pressure between the surfaces of watersnow/ice and the mineral. This can also for surfaces of ice (without a mineral counterpart) be 
386

387

388

389

390

391

392

393

394

395

396

397

398

399

400

401

402

403

404

405

406

described in terms of "premelting" of ice (Dash et al., 2006) by attractive van der Waals force acting upon the uppermost surface layers of snow/ice (cf. Fig. 9.).

This attractive van der Waals force $\mathrm{F}_{\mathrm{vdW}}$, acting per area $\mathrm{F}$ upon the surface of ice of volume $\mathrm{V}=\mathrm{F} \mathrm{d}$ on a mineral surface $\mathrm{F}$ is given in case of parallel interfaces by

$$
\mathrm{F}_{\mathrm{vdW}}=\frac{\mathrm{A}_{\mathrm{Ilm}}}{6 \pi \mathrm{d}^{3}} \mathrm{~F}
$$

$\mathrm{A}_{\mathrm{Ilm}}$ is the Hamaker constant for the interaction of substances "I" (ice) and "m" (mineral) in presence of interfacial water "l" in between. This force acts also between the molecules of water ice at and very near to the surface of ice, which therefore is prone to "premelting". This configuration is described schematically in Fig. 10. The related depressed freezing temperature can in general be shown to be related to different acting pressures, as interfacial melting (premelting) via $\mathrm{F}_{\mathrm{vdW}}$, via curvature melting in course of surface tension, and pressure melting via $\left(p_{L}-p_{m}\right)\left(\left(\rho_{S} / \rho_{L}\right)-1\right)$ by

$$
\rho_{S} \mathrm{q} \frac{\mathrm{T}_{\mathrm{m}}-\mathrm{T}}{\mathrm{T}_{\mathrm{m}}}=\frac{\mathrm{A}}{6 \pi \mathrm{d}^{3}}+\kappa \sigma+\left(\mathrm{p}_{\mathrm{L}}-\mathrm{p}_{\mathrm{m}}\right)\left(\frac{\rho_{\mathrm{S}}}{\rho_{\mathrm{L}}}-1\right) .
$$

(cf. Dash et al., 2006, Wettlaufer and Worster, 2006). $\mathrm{T}_{\mathrm{m}}$ is the standard melting temperature, $\Delta \mathrm{T}=\mathrm{T}_{\mathrm{m}}-\mathrm{T}$ is called the freezing point depression, $\mathrm{q}$ is the latent heat, $\rho$ and $\mathrm{p}$ represent mass density and pressure, respectively, and the indices $\mathrm{L}$ and $\mathrm{S}$ indicate the solid (i.e. ice) and the liquid state.

The limiting minimum temperature of the liquid phase of the water layer below the bulk melting temperature $T_{m}$ is in case of acting van der Waals forces only, given by

$$
\mathrm{T}=\mathrm{T}_{\mathrm{m}}\left(1-\frac{\mathrm{A}}{6 \pi \mathrm{q} \rho_{\mathrm{S}} \mathrm{d}^{3}}\right)
$$

Fig. 11. shows the limiting minimum temperature for interfacial water to remain liquid in dependence on layer thickness and for the range of typical Hamaker constants in nature. As shown in Fig. 12., interfacial water may exist down to about $150 \mathrm{~K}$, as it has experimentally 
410 been verified by Person and Derbyshire (1974). Furthermore, the existence of "unfrozen"

411 water in subzero temperature soils has also been demonstrated and studied by Anderson

412 (1968) and Anderson et al. (1973). Note that the thickness of the layer of undercooled liquid

413 interfacial water is often measured in film-like "monolayers" (of $0.35 \mathrm{~nm}$ ), which are to be

414 understood as an orienting average value, not as a stringent geometrical model.

$$
\mathrm{d}=\left(\frac{\mathrm{A} \mathrm{T}_{\mathrm{m}} / 6 \pi}{\rho_{\mathrm{S}} \mathrm{q} \Delta \mathrm{T}}\right)^{1 / 3}
$$

418 This limiting temperature can get lowered in brines by adding salts, which also tend to

419 increase the thickness $d$ of the layer. Fig. 11. and 12. indicate that liquid interfacial water must 420 exist on Mars in a temperature band below the melting temperature. These temperatures can 421 be reached at polar latitudes at daytime conditions and in the vicinity of the snow/ice interface above an insolation-heated ground, and it can remain "stable" for hours until the ice has left by daytime sublimation or until cooling starts at late afternoon hours (cf. Fig. 12.).

Comparatively high sub-surface temperatures, which may approach the melting point (with the consequence of possible temporary melting) can be expected in course of effective cooling at the surface of insolated ice/snow (due to sublimation and RI re-radiation) but with heat accumulation in an insolation-absorbing sub-surface, if the thermal conductivity is sufficient small. At least, this will strengthen the possible appearance and amount of interfacial water.

Undercooled liquid interfacial water will be able to flow downhill on slopes, being that way a driver of rheologic processes, and parts of it also may seep downward into the subsurface.

433 This infiltrated water will refreeze in the cooler lower subsurface layers. Resulting erosion 
435

436

437

438

439

440

441

442

443

444

445

446

447

448

449

450

451

452

453

454

455

456

457

458

459

water. The final result will finally be a stress built-up in the upper subsurface. This may lead to cracks, failures and erosive processes (cf. Fisher 2005).

\subsection{Liquid interfacial water in soil}

The content of liquid interfacial water in porous soil of specific surface $\mathrm{S}_{\mathrm{M}}$, dry mass $\mathrm{m}_{\mathrm{dry}}$ and mass $\mathrm{M}_{\mathrm{H}_{2} \mathrm{O}}$ of liquid interfacial water can simply be estimated via

$$
\mathrm{a}_{\mathrm{m}}(\mathrm{T}, \mathrm{d})=\frac{\mathrm{M}_{\mathrm{H}_{2} \mathrm{O}}(\mathrm{T}, \mathrm{d})}{\mathrm{m}_{\mathrm{dry}}}=\rho_{\mathrm{H}_{2} \mathrm{O}} \mathrm{S}_{\mathrm{M}} \mathrm{d}=\mathrm{S}_{\mathrm{M}} \rho_{\mathrm{H}_{2} \mathrm{O}}\left(\frac{\mathrm{A} \mathrm{T}_{\mathrm{m}}}{6 \pi \mathrm{q} \rho_{\mathrm{S}} \Delta \mathrm{T}}\right)^{1 / 3} .
$$

Fig. 13 shows measured and modeled (by eq. (5)) soil water contents for four different montmorillonites. Obviously, the content of "microscopic", better "nanometric", liquid interfacial water in frozen soil is a macroscopically relevant phenomenon. It may well reach several $10 \%$. This phenomenon is well known as "unfrozen" water in terrestrial permafrost. Analogously to terrestrial permafrost, undercooled liquid interfacial water can on Mars preferably in springtime and after removal of the $\mathrm{CO}_{2}$-ice cover evolve at sites of the waterice covered parts of the polar caps in course of their warming.

\subsection{Rheologic phenomena (downslope flows)}

The insolated but yet frozen and dark ground on slopes may become the cause of a gravitationally driven flow-like down-slope transport of the interfacial water, preferably between the translucent covering water ice layer and the warmer ground, which is heated by insolation (cf. Fig. 14.) towards the melting point temperature. The resulting layer of interfacial water will be able to remain at or near to the melting temperature over longer timespans of hours or so, and thus it must form several monolayers of undercooled liquid 
interfacial water (cf. Fig. 11.). Thus, there can on inclined surfaces, as slopes, form rheologic

461 features as down-flow phenomena. Fig. 14 illustrates that situation. The thickness of that layer

462 is the greatest at temperatures in the vicinity of the melting temperature (cf. Fig. 11.).

463 Depending on grain sizes, that can in the $10 \mathrm{~nm}$ range (and less) become sufficient also for 464 capillary effects to get involved in this wetting and transport process.

466 The flow of liquid interfacial water will be counteracted by friction within the liquid layer.

467 The resulting stationary velocity $\mathrm{v}$ of a particle of radius $\mathrm{R}$ within the liquid layer is given 468 then by

$$
\mathrm{v}=\frac{2 \mathrm{R}^{2}\left(\rho_{\mathrm{P}}-\rho_{\mathrm{W}}\right) \mathrm{g} \sin \alpha}{9 \eta}
$$

The viscosity $\eta$ is given by $\eta=1.3810^{-3} \mathrm{~Pa}$ s (Rempel et al., 2001), $\mathrm{g}$ is the gravitational acceleration on the surface, $\alpha$ is the inclination of the slope, and $\rho_{\mathrm{P}}$ and $\rho_{\mathrm{W}}$ are the mass densities of the particle and of the water, respectively. Obviously, diurnal downslope flow distances up to about $1 \mathrm{~m}$ can be estimated to be reachable in case of the above described slope model (Fig. 15.).

Fig. 5., 6., 7., 8. give examples of possibly related flow-like features on a Martian slope, as observed by HiRISE and studied in the view of the propagation properties by A. Kereszturi et al. at Collegium Budapest (Kereszturi et al. 2008). The diurnal progress is about $1 \mathrm{~m}$, but these flow-like movements can, of course, be effective over only a few hours a day. So, the real propagation velocity in the few daily "active hours" is correspondingly larger. Probably, the presence liquid interfacial water can also have an influence on its optical properties by

482 solving coloring chemical substances from the solid subsurface materials, what can support 483 the heating process further. 


\subsection{Erosion and failure}

486

487 In water-filled pores, refreezing of liquid undercooled interfacial water ice will cause erosion.

488 The phase change from liquid water to ice results in volume increase $(\Delta \mathrm{V})$ of about $\Delta \mathrm{V} / \mathrm{V}=$ $4899 \%$ and will cause a pressure or elastic stress in the ice/mineral matrix. This stress can cause 490 failure and cracks with erosive results. Therefore, erosion advances in course of refreezing of 491 interfacial water, when the seasonal temperatures approach the local freezing point 492 temperature. In case of the presence of a water ice cover of the surface, seepage and 493 infiltration of interfacial water and its refreezing in the subsurface will happen when the frost 494 point temperature will be reached daytime (in spring) and will decrease below during 495 nighttime.

496

497 The erosive stress $\tau$ due to refreezing water can be estimated via

$$
\tau=\frac{\mathrm{E}}{1-2 v} \frac{\Delta \mathrm{V}}{\mathrm{V}} .
$$

499 E is Young's modulus, and $v$ is Poisson's constant. Typical values for snow and water ice are

$500 \mathrm{E} \approx(1-10) 10^{9} \mathrm{~Pa}$, and $v \approx 0.2-0.5$ given by Mellor $(1975)$. With $\Delta \mathrm{V} / \mathrm{V}=0.09$, this 501 indicates that the related stress can cause erosive destruction around $1 \mathrm{GPa}$. For materials to 502 fail by brittle structure, there is usually a linear correlation between uniaxial compressive 503 strength $\sigma$ and Young's modulus with $\sigma / \mathrm{E} \approx(2-3) 10^{-3}$ (Mellor, 1975). Compressive 504 stresses are for snow between $(1-10) \mathrm{MPa}$ (Mellor, 1975). Therefore, refreezing driven 505 stresses can become the cause of erosive destruction in ice/snow mixtures.

\section{9. Conclusions}


509 Based on observations, narrow, confined, dark slope streaks emanate from Dark Dune Spots

510 during local spring at the observed three craters. These streaks always start from features

511 called Dark Dune Spots, they stretch and move downward, and follow the topography of the

512 depressions between the small scale ripples, producing a branching pattern. Gravity-driven

513 processes can let streaks grow in time, with a speed up to $1.4 \mathrm{~meter} / \mathrm{sol}$, as derived from

514 observations. This agrees in the order of magnitude with model estimates. These movements

515 were observed when the temperature was above the carbon dioxide frost point, and up to

$516250 \mathrm{~K}$, suggesting that this process is not related to carbon dioxide frost and therefore is

517 possibly connected to liquid interfacial water, if water ice is inside the spots. After the

518 darkening of a certain surface area, brightening may follow as the dark flow front has passed

519 by, probably by refreezing of frost, or the phase change of surface material. Unfortunately

520 today only CRISM data has enough spatial resolution to analyze the possible presence of

521 water ice inside spots, but the publicly available data does not meet the required locations and

522 seasonal periods together.

523

524 Taking the assumption that water ice is present inside the spots, interfacial water driven

525 process may produce the observed phenomena. Based on thermodynamics, it can be stated,

526 that interfacial liquid water must, at least temporarily, be present on the Martian surface,

527 particularly in the shrinking and warming seasonal water ice covered terrain. Rheologic, flow-

528 like phenomenon at inclined surfaces, which are caused by liquid interfacial water between a

529 covering ice sheet and the warmed-up mineral surface are therefore to be expected to happen

530 on present Mars. As a result, interfacial water may produce change in the appearance of the

531 dune' surface by 1 . seeping and causing sublimation of surface frost cover, 2 . by produce

532 sliding of lubricated grains above each other and 3. by refreezing produced stress and

533 movement in the grain structure. Our computations and model show that such processes are

534 reasonable under the present surface conditions and satisfactorily interpret the observed 
535 movement of springtime streaks. The presence of interfacial water at the observed features

536 even may have astrobiological consequences (Horváth et al. 2001, Gánti et al. 2003, Pocs et

537 al. 2004, Szathmary et al. 2007) too.

538

539 14. Acknowledgment

540

541 This work was supported by the ESA ECS-project No. 98076 and the Pro Renovanda Cultura

542 Hungariae Foundation, Student Science Fellowship Award. 
543

544

545

546

547

548

549

550

551

552

553

554

555

556

557

558

559

560

561

562

563

564

565

566

567

568

\section{References}

Aharonson, O., Schorghofer N., Gerstell, F.M., 2003. Slope streak formation and dust deposition rates on Mars. J. of Geophys. Res. 108, E12, 5138, doi:10.1029/2003JE002123.

Anderson, D.M., 1968. Undercooling, Freezing Point Depression, and Ice Nucleation of Soil Water, Israel Journal of Chemistry, 6, 349-355.

Anderson, D.M., Tice A.T., McKim, H.L. 1973. The unfrozen water and apparent specific heat capacity of frozen soils, in North American Contribution, Permafrost, second. Internatl. Conference, 289-296, Yakutsk, National Academy of Sciences, Washington D.C.

Beyer, R.A.; Chuang, F.C., Thomson, B.J., Milazzo, M.P., Wray, M. P., 2008. Martian Slope Streak Brightening Mechanisms, $39^{\text {th }}$ Lunar Planet. Sci. Conf. abstract 2538.

Bibring, J. P., Langevin, Y., Poulet, F., Gendrin A., Gondet, B., Berthé, M., Soufflot, A., Drossart, P., Combes, M. Bellucci, G., Moroz, V., Mangold, N., Schmitt, B. \& the OMEGA team, 2004. Perennial water ice identified in the south polar cap of Mars, Nature, 428, 627630.

Bibring, J.P., Y. Langevin, A. Gendrin, B. Gondet, F. Poulet, M. Berthe, A. Soufflot, R. Arvidson, N. Mangold, J. Mustard, P. Drossart \& the OMEGA team, 2005. Surface diversity as revealed by the OMEGA/Mars Express Observations, Science, 307, 1576-1581

Bodnar, R.J., 2001. PTX phase equilibria in the $\mathrm{H}_{2} \mathrm{O}-\mathrm{CO}_{2}$-salt system at Mars near-surface conditions. 32 $2^{\text {th }}$ Lunar Planet. Sci. Conf., abstract 1689. 
570 Brass, G.W., 1980. Stability of brines on Mars, Icarus, 42, 20-28.

571

572 Christensen, P., Anderson, D., Chase, S.C., Clark, R.N., Kieffer, H.H., Malin, M.C., Pearl, 573 J.C., Carpenter, J.B., Nuno, B.F., 1992. Thermal Emission Spectrometer Experiment: Mars 574 Observer Mission, J. of Goephys. Res., 97, 7719-7734.

Christensen, P.R.; Kieffer, H.H., Titus, T.N., 2005. Infrared and Visible Observations of 577 South Polar Spots and Fans, American Geophysical Union, Fall Meeting, abstract P23C-04.

578

579

Chuang, F.C.; Beyer, R.A., McEwen, A.S., Thomson, B.J. 2007. HiRISE observations of 580 slope streaks on Mars, Geophysical Research Letters, 34/20, CiteID L20204.

581

582 Clow, G.D., 1987. Generation of liquid water on Mars through the melting of a dusty 583 snowpack, Icarus 72, 95-127.

584

585

Dash, J.G., Rempel, A.W., Wettlaufer, J.S., 2006. The physics of premelted ice at its 586 geophysical consequences, Annu. Rev. Fluid Mech., 38, 427-452.

Fisher D.A., 2005. A process to make massive ice in the Martian regolith using long-term 589 diffusion and thermal cracking, Icarus, 179. 387-397.

Gánti, T., Horváth, A., Bérczi, Sz., Gesztesi, A., Szathmáry, E. 2003. Dark dune Spots:

592 Possible Biomarkers on Mars? Origins of Life and Evolution of the Biosphere, 33, 515-557. 
595 Gánti T., Bérczi, Sz., Horváth, A., Kereszturi, A., Pócs, T., Sik, A., Szathmáry, E., 2006.

596 Hypothetical time sequence of the morphological changes in global and local levels of the

597 dark dune spots in polar regions of Mars, $37^{\text {th }}$ Lunar Planet. Sci. Conf., abstract 1918 598

599

Haberle, R.M., McKay, C.P., Schaeffer, J., Cabro, N.A., Grin, E.A., Zent A.P. and Quinn, R., 600 2001. On the possibility of liquid water on present-day Mars. J. Gephys. Res.. 106, E10, $601 \quad 23317-23326$.

602

603 Hamaker, H.C., 1937. The London-van der Waals Attraction between Spherical Particles, 604 Physica, IV, 10, 1058.

605

606 Head, J.W., Marchant, D.R., Dickson, J.L., Levy, J.S. and Morgan, G.A., 2007a. Slope 607 streaks in the Antarctic Dry Valleys: characteristics, candidate formation mechanisms, and 608 implications for slope streak formation in the Martian environment, $7^{\text {th }}$ International Conf. on 609 Mars, abstract 3114.

610

611 Head, J.W., Marchant, D.R., Dickson, J.L., Levy, J.S., Morgan, G.A., Kreslavsky M., $2007 b$.

612 Mars gully analogs in the Antarctic Dry Valleys: geological settings and processes, 7th 613 International Conf. on Mars, abstract 3118.

614

615 Hecht, M.H., 2002. Metastability of Liquid Water on Mars, Icarus, 156, 373-386, 616 doi:10.1006/icar.2001.6794.

617

618 Horváth, A., Gánti T., Gesztesi A., Bérczi Sz., Szathmáry E. 2001. Probable evidences of 619 recent biological activity on Mars: appearance and growing of dark dune spots in the south 620 polar region, $32^{\text {nd }}$ Lunar Planet. Sci. Conf., abstract 1543. 
622 Horváth, A. Kereszturi, Á. Bérczi, Sz. Sik, A., Pócs, T., Gesztesi, A., Gánti, T., Szathmáry, E. 623 2005. Annual change of Martian DDS-seepages, $35^{\text {th }}$ Lunar and Planet. Sci. Conf., abstract 6241128.

625

626 Horváth, A., Kereszturi, Á., Bérczi, Sz., Sik, A., Pócs, T., Ganti, T. \& Szathmáry, E. 2009. 627 Analysis of dark albedo features on a Southern Polar dune field of Mars, Astrobiology in 628 press

629

630 Kereszturi, A. Sik, Horvath, A., D. Reiss, Jaumann, R., Neukum G., 2007. Season-dependent 631 behavior of Dark Dune Spots on Mars, $38^{\text {th }}$ Lunar and Planet. Sci. Conf., abstract 1864.

632

633 Kereszturi, A., Möhlmann, D., Berczi, Sz., Horvath, A., Ganti, T., Kuti, A., Pocs, T., Sik, A., 634 Szathmary, E., 2008. Analysis of possible interfacial water driven seepages on Mars, $39^{\text {th }}$ 635 Lunar and Planet. Sci. Conf., abstract 1555.

636

637 Kieffer, H.H., Titus, T.N., 2001. TES Mapping of Mars' North Seasonal Cap, Icarus, 154, $638 \quad 162-180$.

639

640 Kieffer, H.H., 2003. Behavior of Solid $\mathrm{CO}_{2}$ on Mars: A Real Zoo. $6^{\text {th }}$ International Conf. on 641 Mars, abstract 3158.

642

643 Kieffer, H.H., Christensen, P.R., Titus, T.N., 2006. $\mathrm{CO}_{2}$ jets formed by sublimation beneath 644 translucent slab ice in Mars' seasonal south polar ice cap, Nature, 442, 793-796. 
646 Knauth, L.P., Burt, D.M., 2002. Eutectic Brines on Mars: Origin and Possible Relation to

647 Young Seepage Features, Icarus, 158, 267-271.

648

649 Kossacki, K.J., Markiewicz, W.J., 2008. Martian hill-gullies, surface and sub-surface 650 moisture, Mars Water Cycle Workshop, Paris.

651

652 Langevin, Y., Bibring, J.P., Douté, S., Vincendon, M., Poulet, F., Gondet, B., Schmitt, B., 653 Forget, F., Montmessin, F. and the OMEGA team. 2006. CO2 ice and H2O ice in the seasonal 654 caps of mars during the spring retreat, phase. $4^{\text {th }}$ Mars Polar Sci. Conf., abstract 8091.

655

656 Malin, M.C., Edgett, K.S., 2000. Frosting and defrosting of Martian polar dunes, $31^{\text {th }}$ Lunar 657 and Planet. Sci., abstract 1056.

658

659 Mellon, M., 1975. A review of basic snow mechanics. Snow Mechanics symposium 251, 660 IAHS Publ. 114.

661

662 Mellon, M.T., Phillips, R.J., 2001. Recent gullies on Mars and the source of liquid water, J. 663 Geophys. Res., 106, 0, 1-15.

664

665 Motazedian, T., 2003 Currently Flowing Water on Mars. 34 ${ }^{\text {th }}$ Lunar Planet. Sci. Conf., 666 abstract 1840.

667

668 Möhlmann, D., 2004. Water in the upper Martian surface at mid- and low-latitudes: presence, 669 state, and consequences, Icarus, 168, 318-323.

670 
671 Möhlmann, D., 2008. The influence of van der Waals forces on the state of water in the 672 shallow subsurface of Mars, Icarus, 195, 131-139.

673

674 NASA Press Release 2008. no. 08-246, 2008.09.29.

675

676 Pearson, T.T., Derbyshire, W., 1974. NMR studies of water adsorbed on a number of silica 677 surfaces, J. Coll. Interf. Sci., 46 (2), 232-248.

678

679 Piqueux, S., Byrbe, S. Richardson, M.I., 2003. Sublimation of Mars's Southern seasonal $\mathrm{CO}_{2}$ 680 ice cap and the formation of spiders. J. Geophys. Res., 108, 5084.

681

682 Pócs, T., Horváth, A., Gánti, T., Bérczi, Sz., Szathmáry, E., 2004. Possible Crypto-Biotic683 Crust on Mars? In: Exo/Astrobiology, Proc. Third Eur. Workshop, ESA SP-545, 265-266.

684

685 Reiss, D., van Gasselt, S., Neukum, G., Jaumann, R., 2004. Absolute dune ages and 686 implications for the time of formation of gullies in Nirgal Vallis, Mars. 35th Lunar Planet. 687 Sci. Conf., abstract 1639.

688

689 Rempel, A.W., Wettlaufer, J.S., Worster, M.G., 2001. Interfacial premelting and the 690 thermomolecular Force: Thermodynamic Buoyancy, Phys. Rev. Lett., 87 No.8, 088501-504.

691

692 Ryan, J.A., Sherman, R.D., 1981. $\mathrm{H}_{2}$ O Frost Point Detection on Mars?, J. Geophys. Res., 86, $693 \quad \mathrm{C} 1,503-511$.

694 
695 Schmitt, B., Douté, S., Langevin, Y., Forget, F., Bibring, J.P., Gondet, B. \& the OMEGA

696 Team. 2005. Northern Seasonal Condensates on Mars by Omega/Mars Express, $6^{\text {th }}$ Lunar 697 Planet. Sci. Conf., abstract 2326.

698

699 Schmitt, B., Schmidt, F., Douté, S., Langevin, Y., Forget, F., Bibring, J.P., Gondet, B. and the 700 OMEGA Team, 2006. Recession of the northern seasonal condensates on mars by 701 OMEGA/Mars Express, $4^{\text {th }}$ Mars Polar Sci. Conf., abstract 8050.

702

703 Schorghofer, N.; Aharonson, O., Gerstell, M.F., Tatsumi, L., 2007. Three decades of slope 704 streak activity on Mars, Icarus, 191, 132-140.

705

706 Smith, D., Neumann, G., Ford, P., Arvidson, R.E., Guinness, E.A., Slavney, S., 1999. Mars

707 Global Surveyor Laser Altimeter Precision Experiment Data Record, NASA Planetary Data 708 System, MGS-M-MOLA-3-PEDR-L1A-V1.0.

710 Szathmáry, E., Horváth, A., Sik, A., Bérczi, Sz., Ganti, T., Pócs, T., Kereszturi, A., 2005.

711 Signs of water runoff and its relation to possible living organisms on Mars, 5th EANA 712 Workshop on Astrobiology, Budapest.

714 Szathmary, E., Ganti, T., Pocs, T., Horvath A., Kereszturi, A., Berzci, Sz., Sik, A. 2007. Life 715 in the dark dune spots of Mars: a testable hypothesis, in Planetary Systems and the Origin of 716 Life, ed. Ralph Pudritz, Paul Higgs, Jonathan Stone, Cambridge University Press.

718 Titus, T.N., 2005. Thermal infrared and visual observations of a water ice lag in the Mars 719 southern summer, Geophysical Research Letters, 32, Issue 24, CiteID L24204. DOI: $72010.1029 / 2005$ GL024211. 
722 Titus, T., 2008. Infrared observations of mars south polar water ice. Mars Water cycle

723 Workshop, Paris.

724

725 Wagstaff, K.L., Titus, N.T., Ivanov, A.B., Castano, R., Bandfield, J.L., 2008. Observation of 726 the north water ice annulus on Mars using THEMIS and TES, Planetary and Space Sceince, 727 56. 256-265.

728

729 Wettlaufer, J.D., M.G. Worster, 2006. Premelting Dynamics, Annual Reviews, 38, 427-452. 
731 Figure captions

732

733 Fig. 1. Comparison of MOC (top) and HiRISE (middle, bottom) images of the same terrains

734 at different dates, showing the similar phenomenon was observed by MGS and MRO. Top 735 row shows $300 \times 300 \mathrm{~m}$ insets of MGS MOC image R07-00938 $\left(\mathrm{Ls}=220^{\circ}\right)$, middle row shows $736300 \times 300 \mathrm{~m}$ insets of HiRISE images PSP-003609-1110 $\left(\mathrm{Ls}=232^{\circ}\right)$ of the same terrains. In the 737 bottom row $80 \times 80 \mathrm{~m}$ segments are visible in magnified version of the middle row, which 738 locations are indicated by black boxes. North is up, the Sun illuminates from the left 739

740 Fig. 2. Example for characteristic morphology of slope streaks. Left: distinction between fan741 shaped (gray) and confined (black) slope streaks based on their appearance and direction of 742 elongation on an $125 \times 125$ meter part of HiRISE image no. PSP_003175_1080. Right: 743 examples for branching morphology of streaks and accumulated pond-like termination. The 744 images are visible up and the graphical representations at bottom

Fig. 3. Development of two passive streaks (top and bottom rows) on 300x300 m sections of HiRISE images no. 3432-1115, 3643-1115, 3709-1115 (from left toward right), acquired at $L s=222.9,233.2,236.4$ respectively. Based on the morphology they moved toward the right (toward the elongated part) previously, but currently they show only darkening and the growth of small segments, which finally coalesce into a continuous streak.

Fig. 4. Change DDSs at three locations in Richardson crater. The 100x100 inset pictures are from HiRISE images (from left to right image no. 3175, 3386, 3597, 3742, 3953, which were acquired at $L s=210.6,220.7,230.9,238.1,248.5)$, showing the development of structures. 
756

757

758

759

760

761

762

763

764

765

766

767

768

769

770

771

772

773

774

775

776

777

778

779

780

781

Fig. 5. Example images of active streaks from Russel crater. The three images from left to right represent subsequent HiRISE images no. 2482, 2548, 2904 which were acquired at $\mathrm{Ls}=178.9 \mathrm{~m} 181.9$ and 197.9 respectively. On the right a graphical representation is visible, showing the movement and its observed speed.

Fig. 6. Temperature-morphology correlation for Dark Dune Spots and slope streaks in Russel crater, with $300 \times 300$ meter sized images of the same terrain are visible at top, where the number of HiRISE images from left to right are 2482-1255, 2548-1255, 2904-1255, which were acquired at $\mathrm{Ls}=178.9,181.8,197.9$ respectively. At bottom the temperature curve is indicated (top curve: daytime, bottom curve: nighttime values). Three vertical lines show the temperatures corresponding to the three periods of seasons at the upper images.

Fig. 7. Temperature-morphology correlation for Dark Dune Spots and slope streaks in an unnamed crater at $68 \mathrm{~S} 2 \mathrm{E}$. Three $100 \times 100$ meter insets from HiRISE images are visible up (from left to right image no. 3432, 3643, 3709, which were acquired at Ls=222.9, 233.2, 236.4 respectively) and TES based annual temperature values are visible below.

Fig. 8. Temperature-morphology correlation for Dark Dune Spots and slope streaks in Richardson crater. Five 100x100 meter insets from HiRISE images are visible up (from left to right image no. $3175,3386,3597,3742,3953$, which were acquired at Ls=210.6, 220.7, 230.9, 238.1, 248.5 respectively) and TES based annual temperature values are visible below, where daytime and nighttime temperatures form two curves on the right.

Fig. 9. The "Sandwich model" of liquid interfacial water (layer thickness d) between ice and surface of a mineral grain. 
782 Fig, 10. Frost point temperature (thick line) and minimum liquidus temperature (thin curve

783 below) in dependence on the (log of the) number density $N$ of water vapor molecules (water

784 molecules per cubic meter). The small area between the two curves is the "band of

785 undercooled liquid interfacial water" (Möhlmann (2008b) in T- $N$ - phase space).

786

787 Fig. 11. Dependence of the thickness d [m] of the liquid interfacial water layer on the limiting 788 temperature $T_{1}[\mathrm{~K}]$ of undercooled water to remain liquid for two Hamaker constant values: $789 \mathrm{~A}=10^{-18} \mathrm{~J}$ (upper curve) and $\mathrm{A}=10^{-19} \mathrm{~J}$ (lower curve).

790

791 Fig. 12. Minimum liquid layer temperature for $\mathrm{A}=10-19 \mathrm{~J}$ (upper gray curve) and $\mathrm{A}=10-18$

$792 \mathrm{~J}$ (lower black curve) in dependence on the layer thickness d. Obviously, liquid interfacial 793 water of about two monolayers in thickness may for appropriate surfaces exist down to about $794150 \mathrm{~K}$.

795

796 Fig. 13. Li-, Na-, Ca-, and K-Montmorillonites (exp.: thick lines, theor: thin lines), according 797 to experimental data of Anderson (1968) and by using eq. (5). Fig. 13. Li-, Na-, Ca-, and K798 Montmorillonites (exp.: thick lines, theor: thin lines), according to experimental data of 799 Anderson (1968) and by using eq. (5). a) Li-montmorillonite reaches up to about $0.8 \mathrm{~g} / \mathrm{g}$ 800 (uppermost curve), b) Na-montmorillonite reaches up to about $0.65 \mathrm{~g} / \mathrm{g}$ (lower right curve), c) 801 Ca-montmorillonite reaches up to about $0.55 \mathrm{~g} / \mathrm{g}$, and d) K-montmorillonite (very similar to 802 Ca-montmorillonite, b) reaches up to about $0.4 \mathrm{~g} / \mathrm{g}$ (nearly overlapping curves in the middle). 803

804 Fig. 14 Geometric slope insulation situation.

805

806 Fig. 15. Maximum diurnal downslope flow distance $\mathrm{L}[\mathrm{m}]$ in dependence on slope inclination.

$807(\mathrm{R}=10-5 \mathrm{~m}, \mathrm{rP}=3000 \mathrm{~kg} \mathrm{~m}-3, \mathrm{rW}=1000 \mathrm{~kg} \mathrm{~m}-3)$.

808 
Table 1.

crater image no. date Ls

Russel (54S 12E)

$$
\begin{aligned}
& 2482 \_1255 \quad 2007.02 .0515: 52 \quad 178.9 \\
& \text { 2548_1255 2007.02.10 16:00 } 181.8 \\
& \text { 2904_1255 2007.03.10 15:57 } 197.9
\end{aligned}
$$

unnamed crater $(68 \mathrm{~S} 2 \mathrm{E})$

$$
\begin{aligned}
& 3432 \_1115 \quad 2007.04 .2015: 55 \quad 222.9 \\
& \text { 3643_1115 2007.05.07 15:51 233.2 } \\
& 3709 \_1115 \quad 2007.05 .1215: 56 \quad 236.4
\end{aligned}
$$

Richardson (72S 180E)

$$
\begin{array}{lll}
3175 \_1080 & 2007.03 .3116: 08 & 210.6 \\
3386 \_1080 & 2007.04 .1716: 04 & 220.7 \\
3597 \_1080 & 2007.05 .0316: 00 & 230.9 \\
3742 \_1080 & 2007.05 .1515: 49 & 238.1 \\
3953 \_1080 & 2007.05 .31 .15: 42 & 248.5
\end{array}
$$



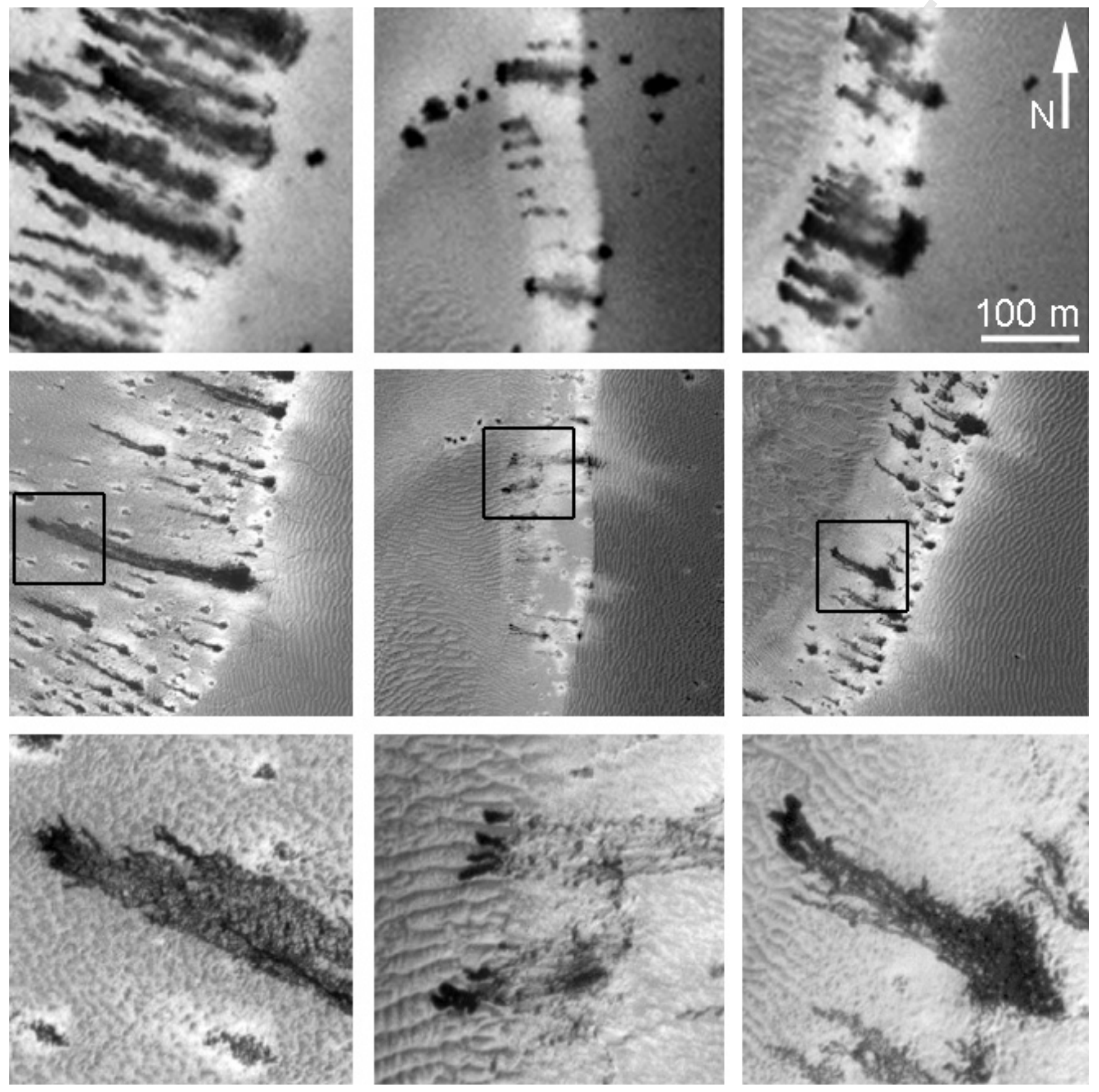

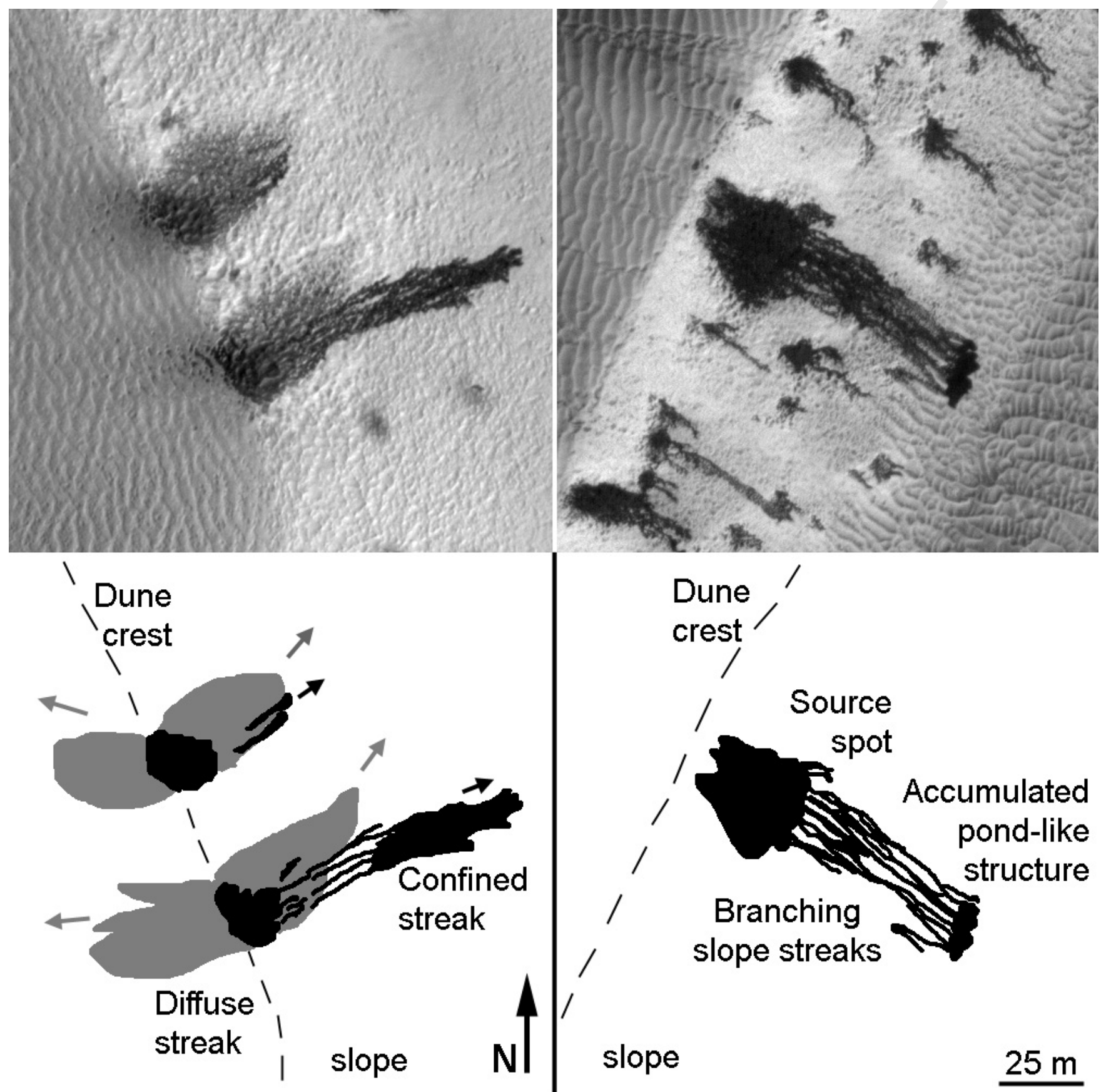

Dune
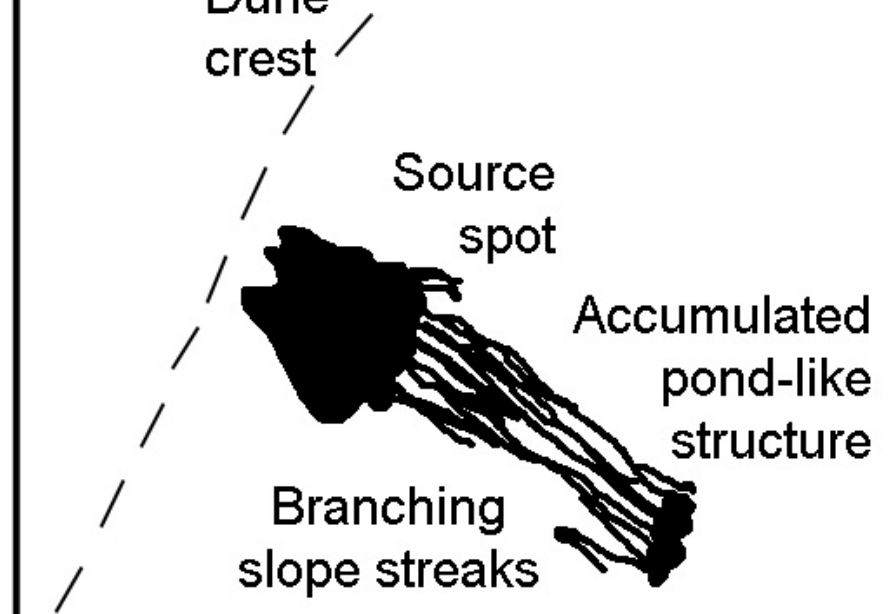

Confined streak

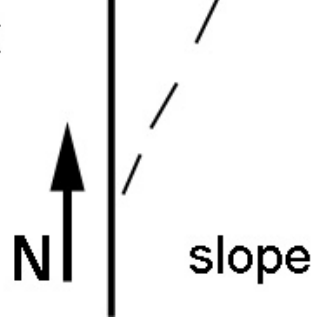

$25 \mathrm{~m}$ 


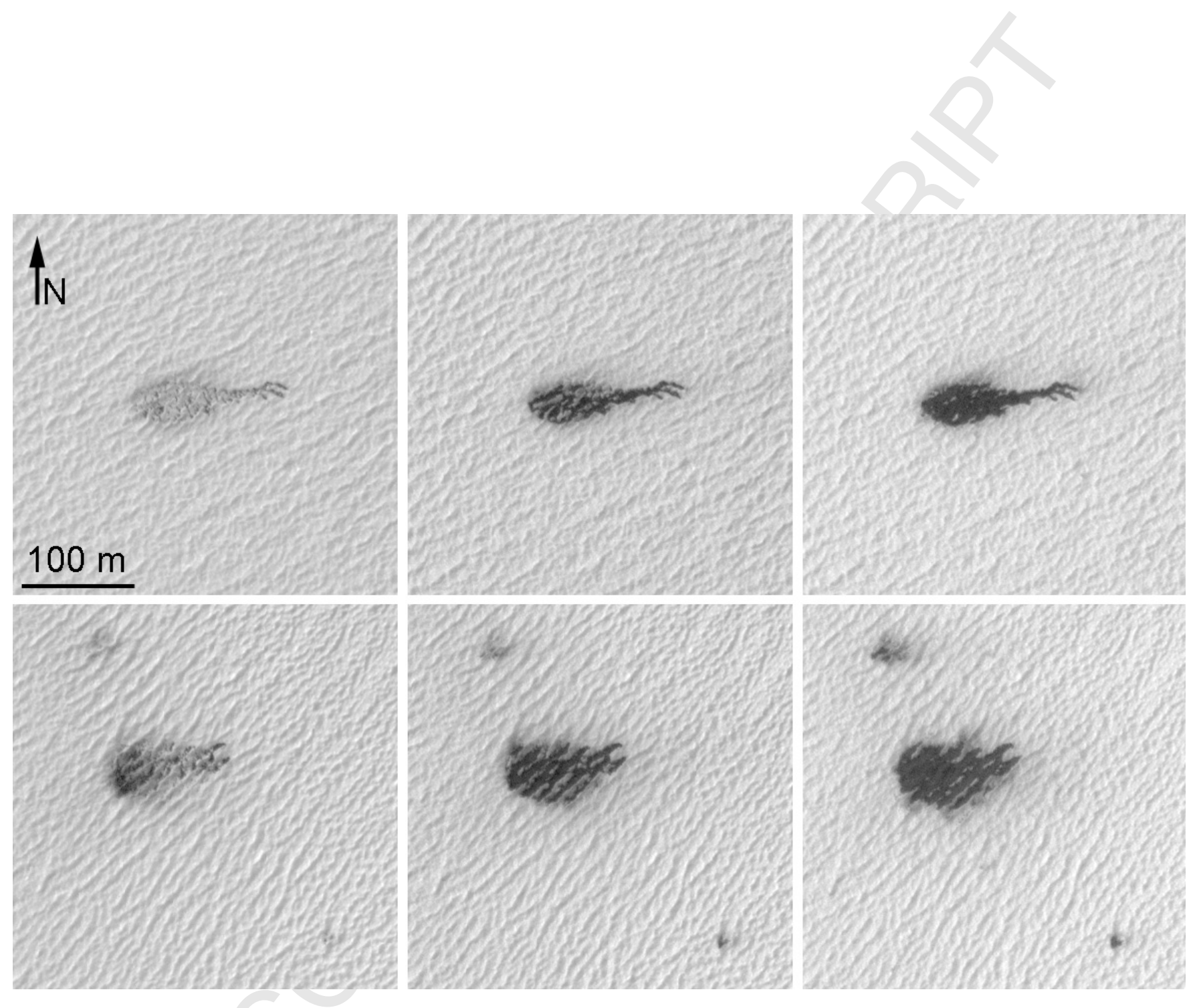



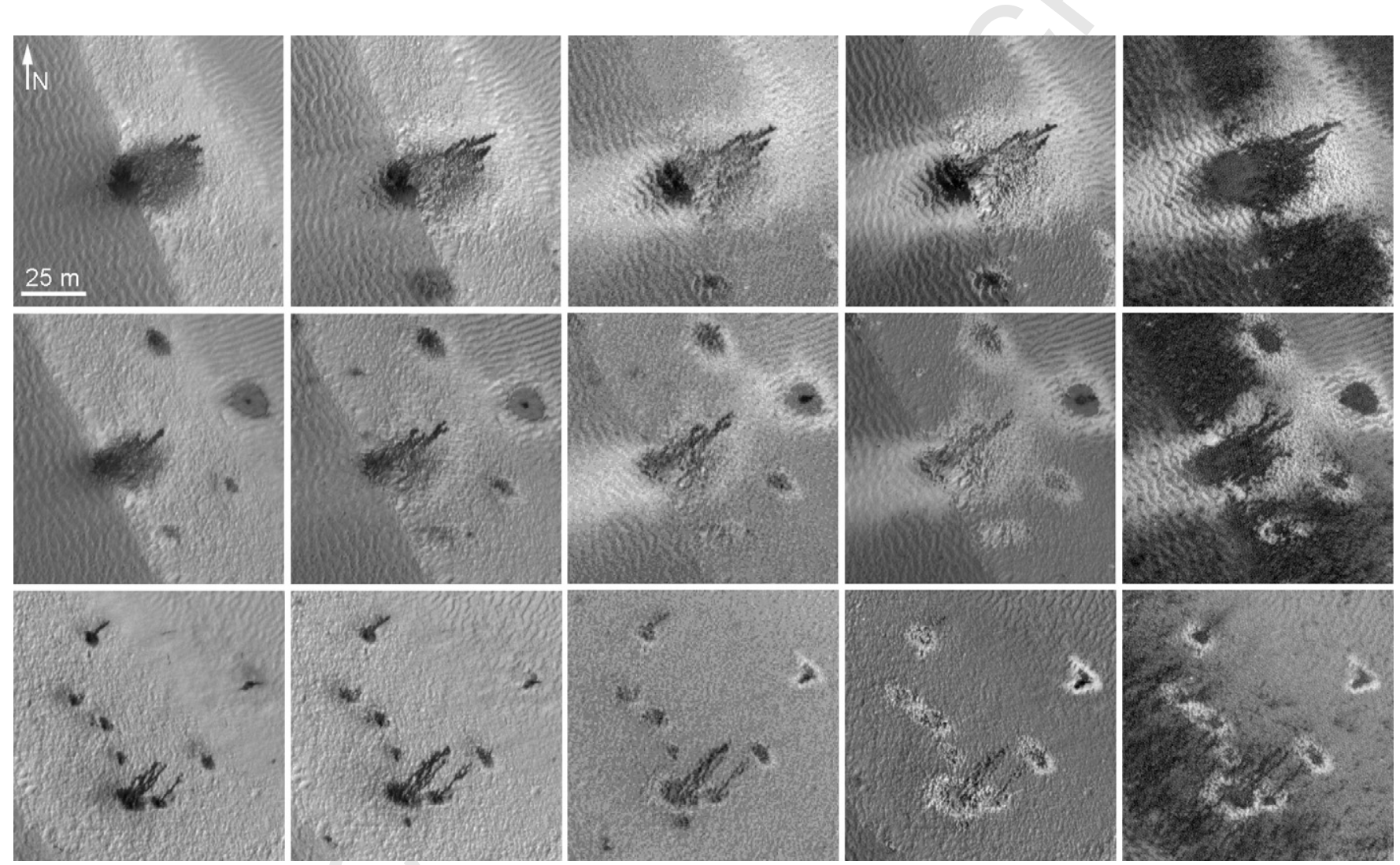

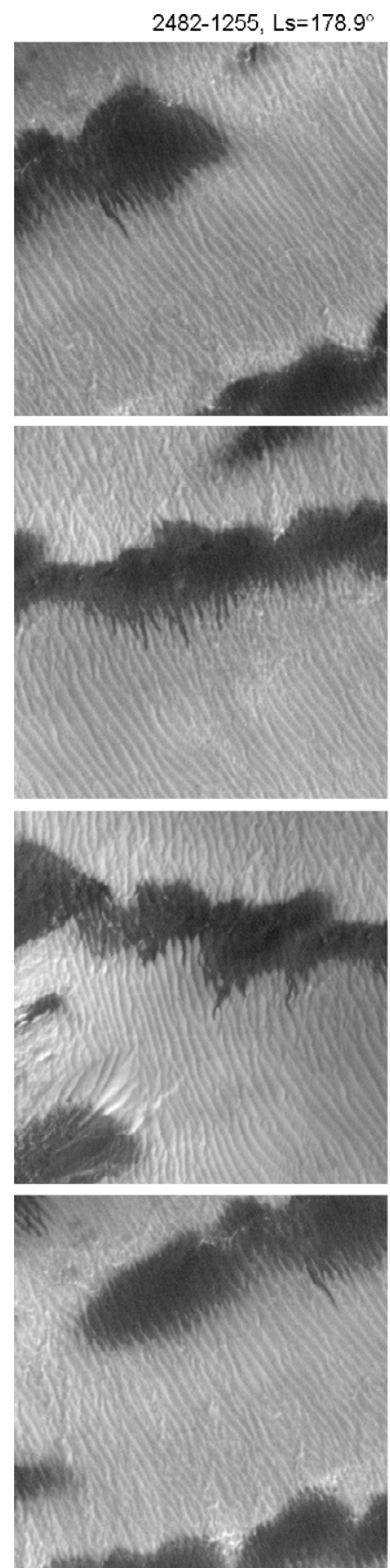

2548-1255, Ls=181. $8^{\circ}$
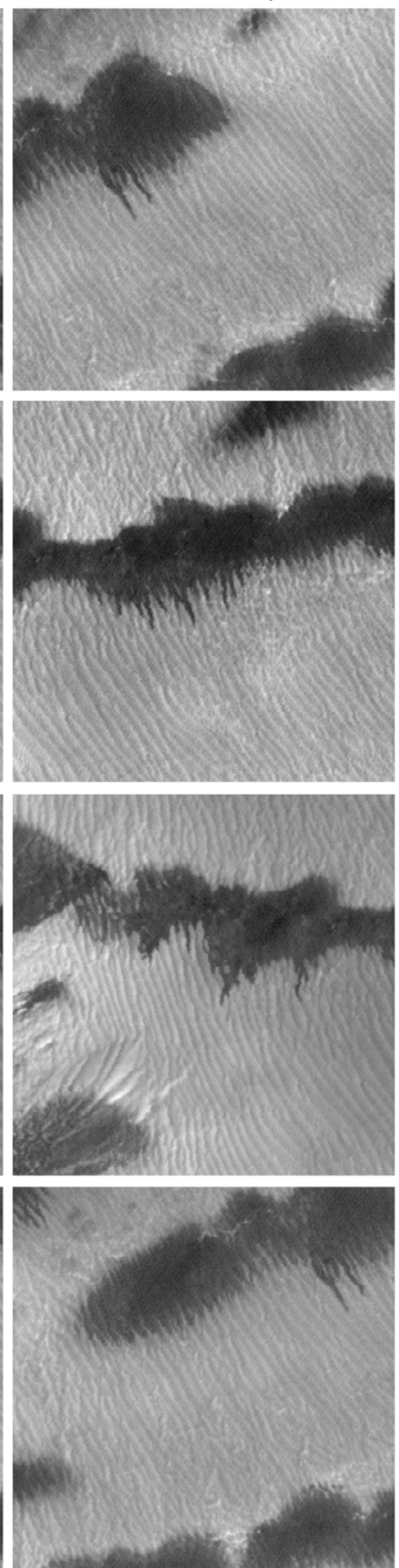

2904-1255, Ls=197.9 $9^{\circ}$

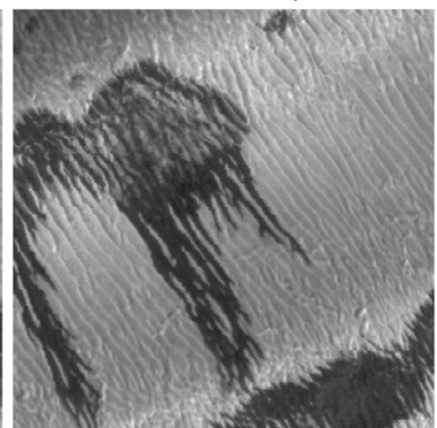

$20 \mathrm{~m}$
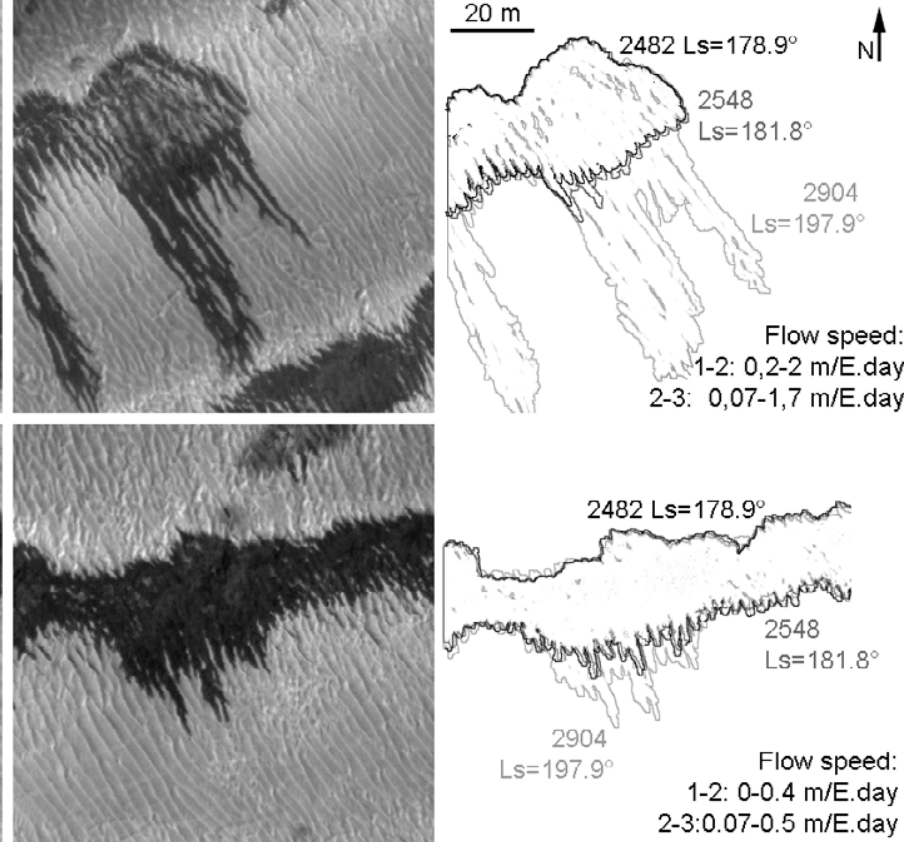

$\mathrm{Ls}=197.9^{\circ}$

Flow speed

1-2: 0-0.4 m/E.day 2-3:0.07-0.5 m/E.day
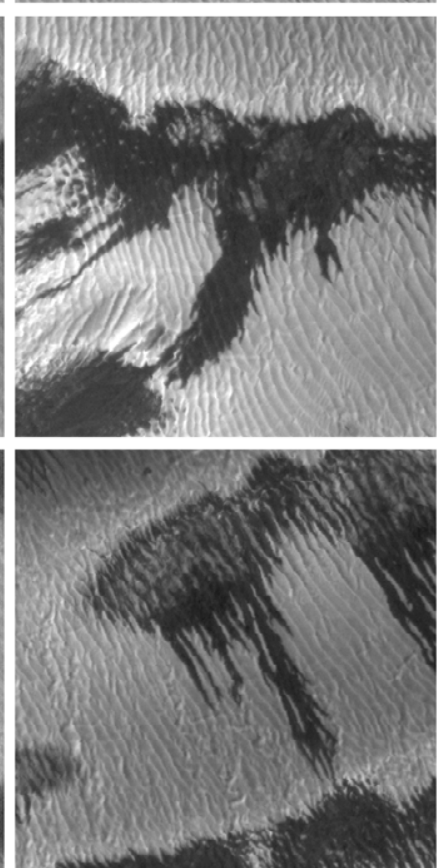

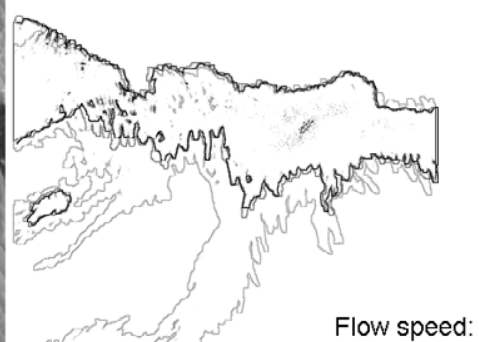

1-2: 0-0.5 m/E. day 2-3: 0.2-1.4 m/E.day

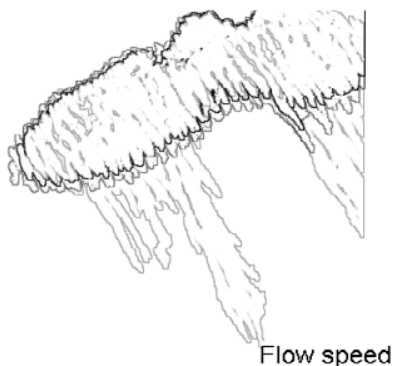

1-2: 0.2-1 m/E-day 2-3: 0.7-1.4 m/E. day 


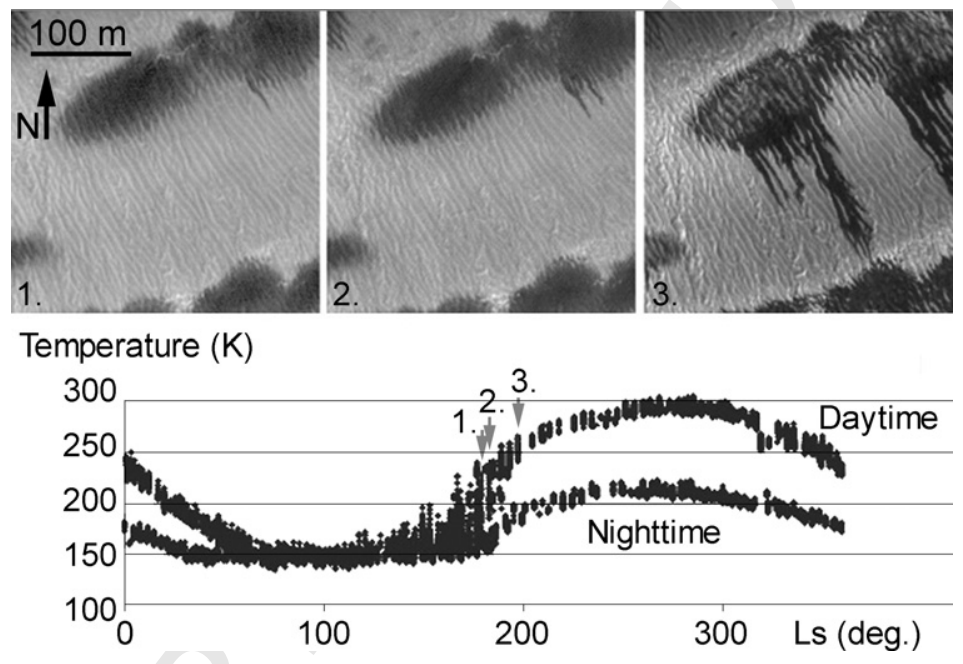




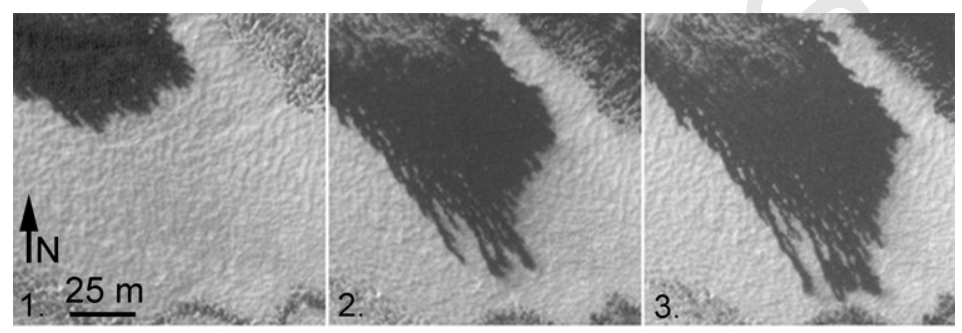

Temperature (K)

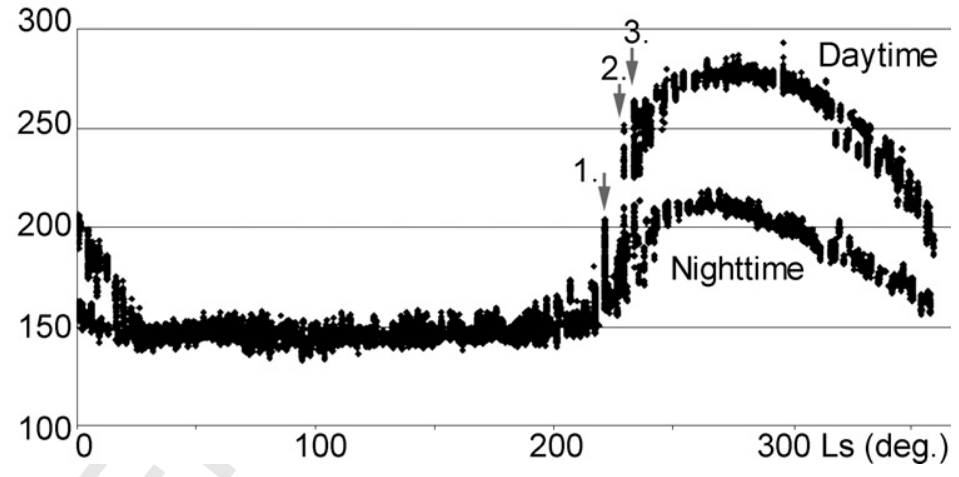




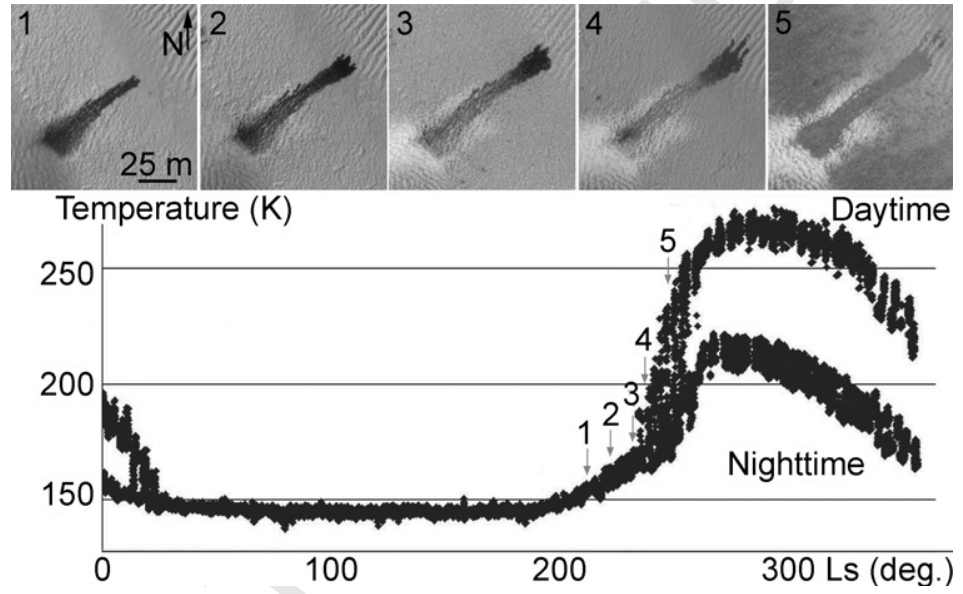




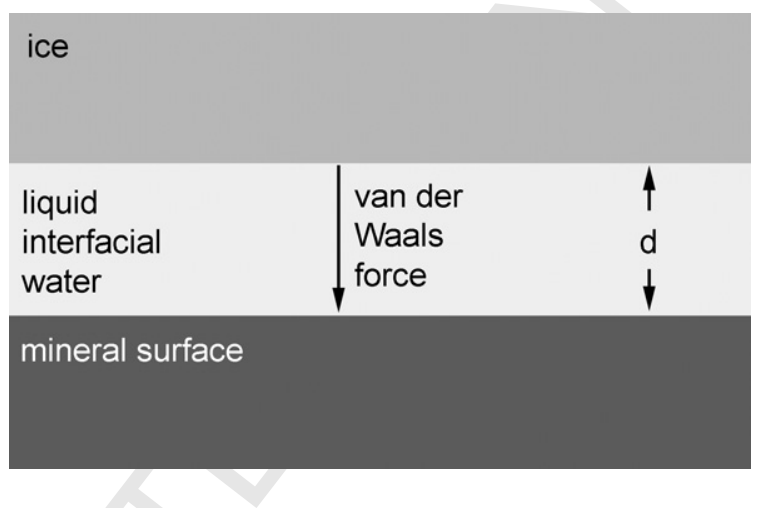




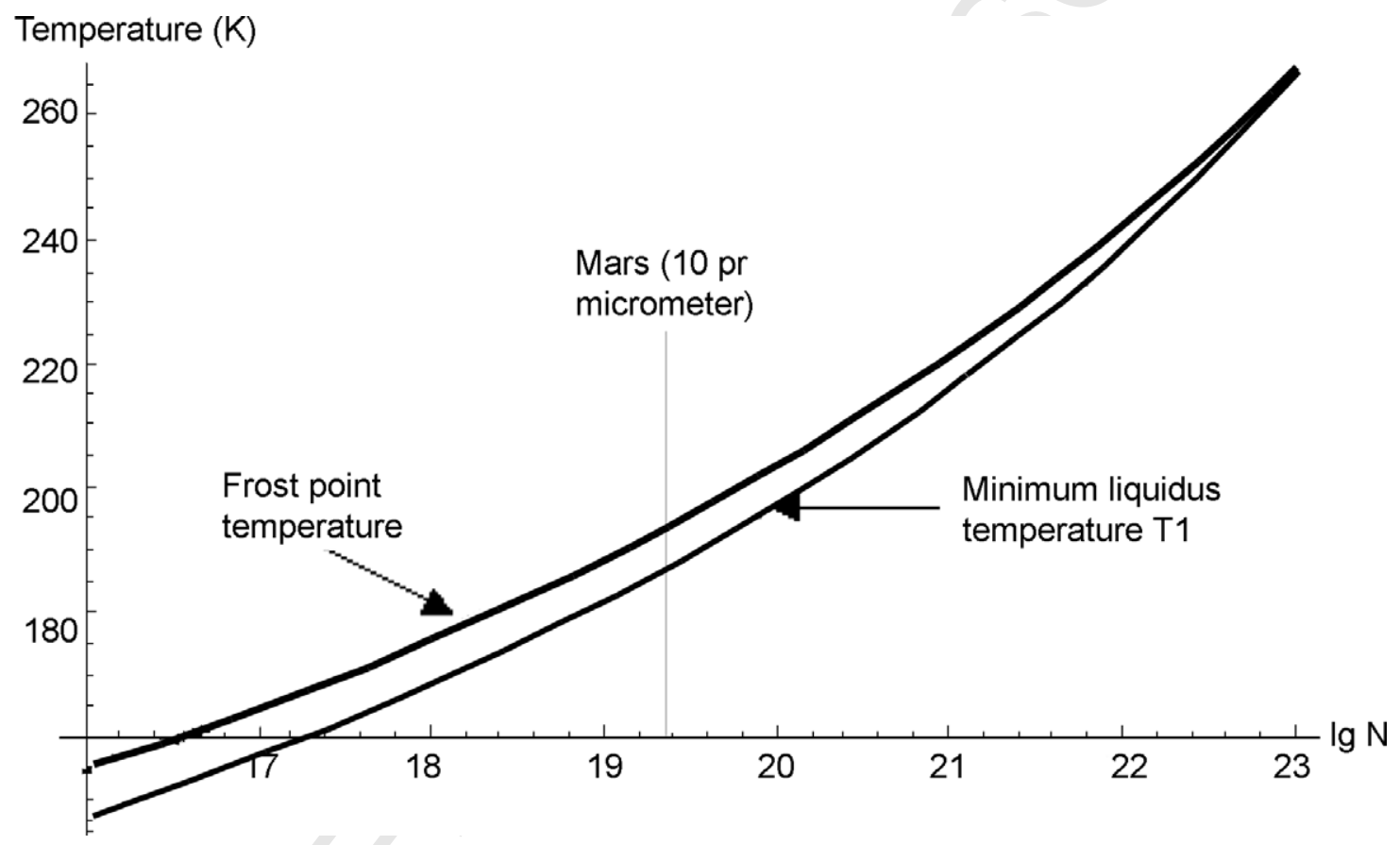




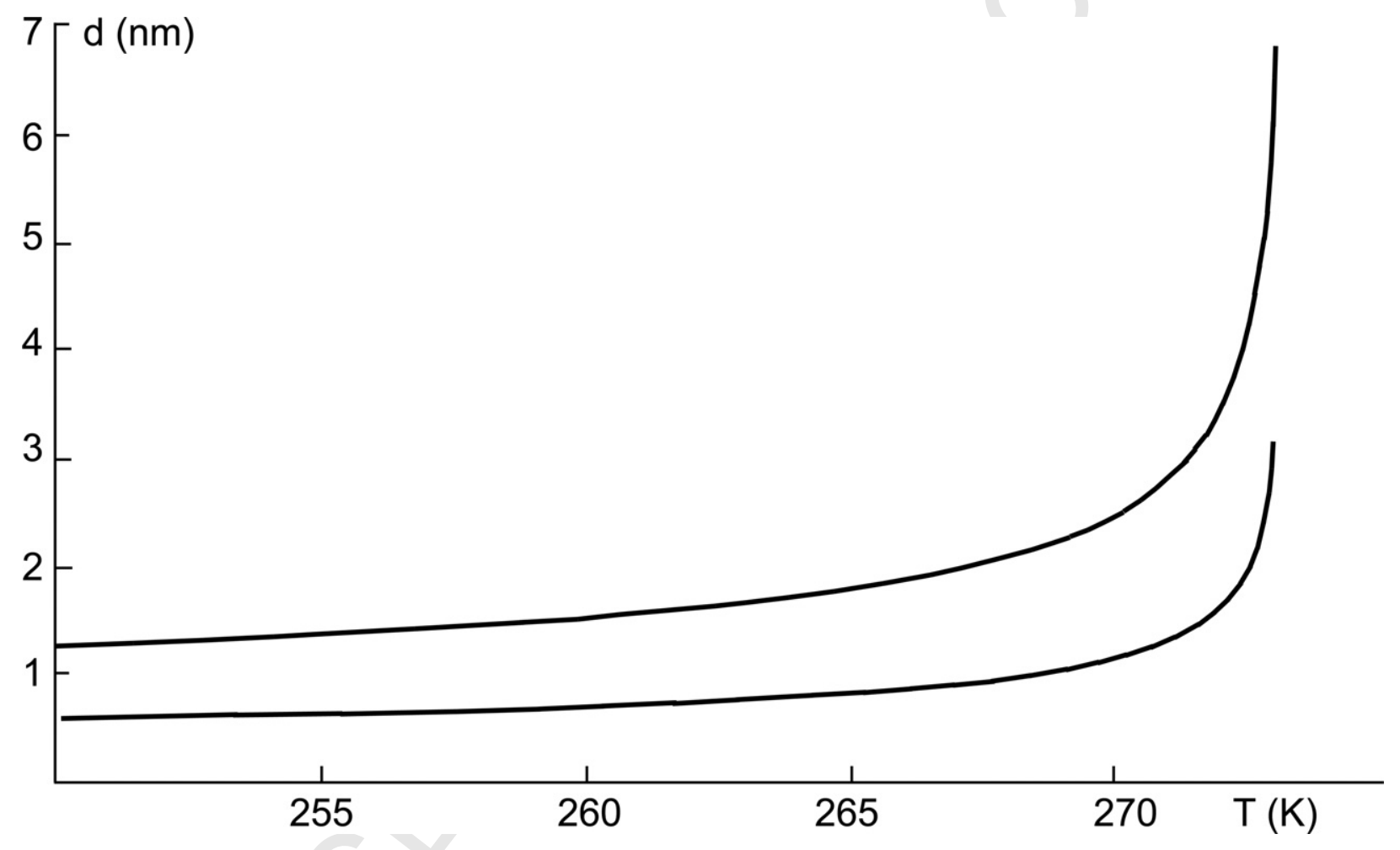




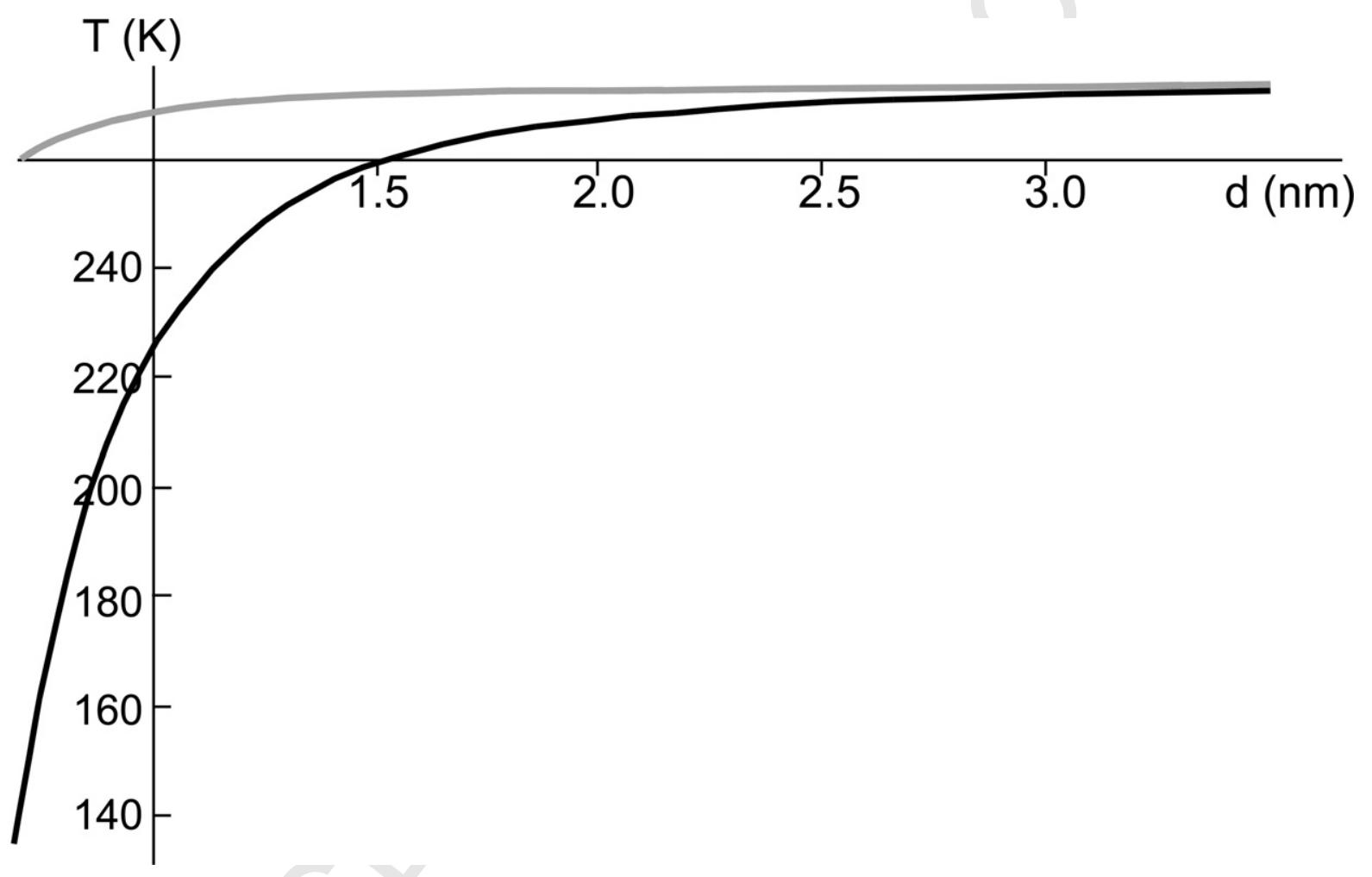




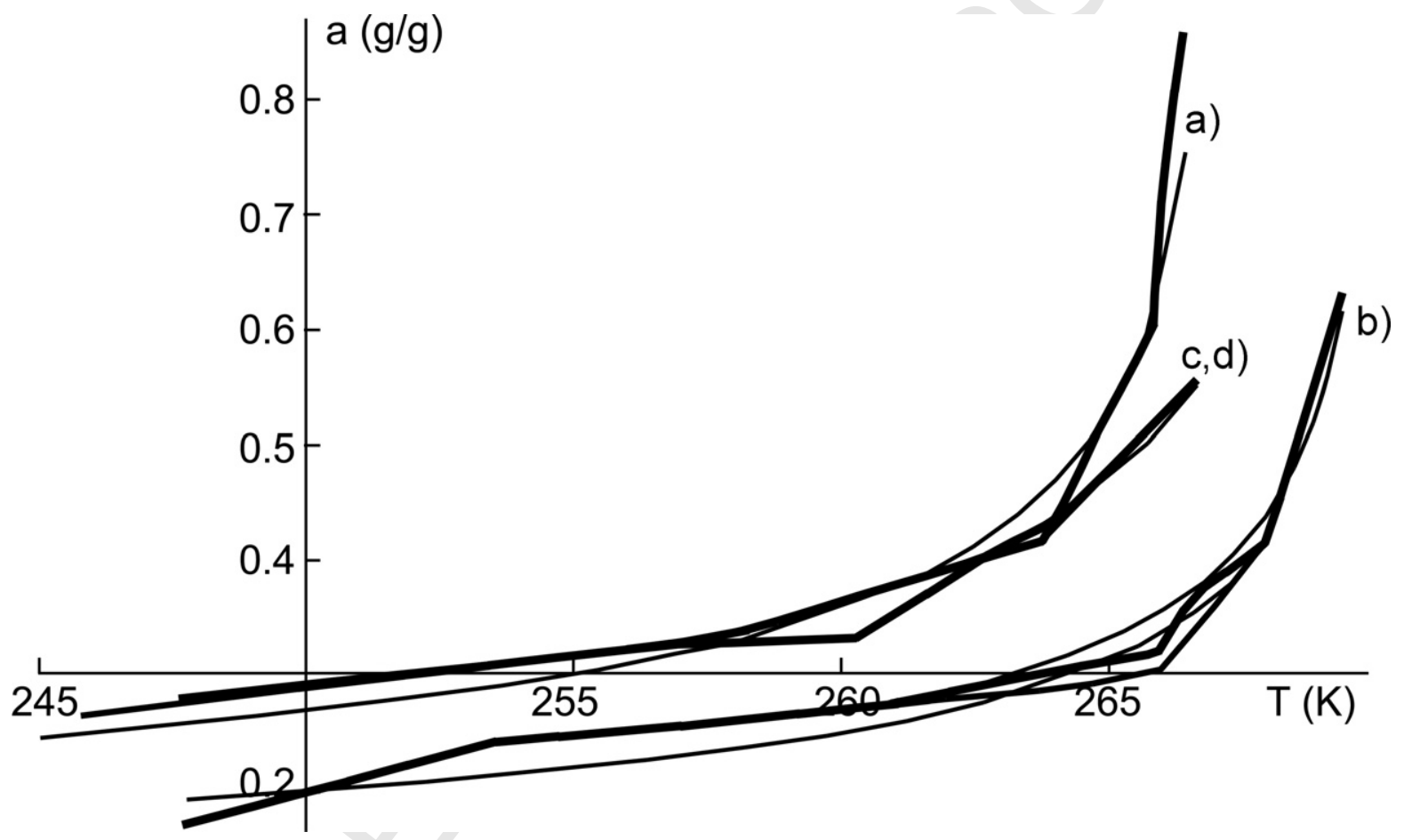




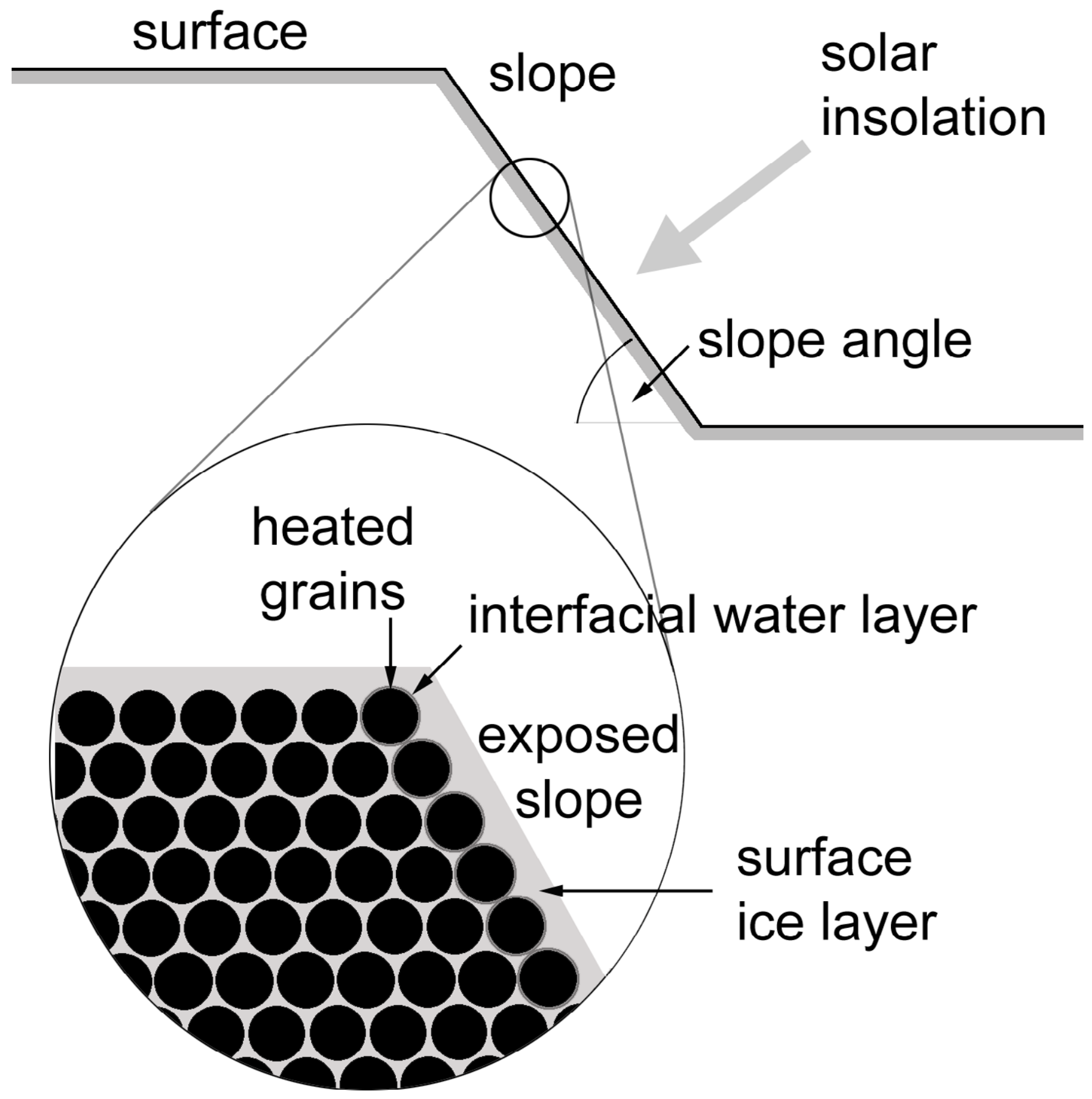


ACCEPTED MANUSCRIPT

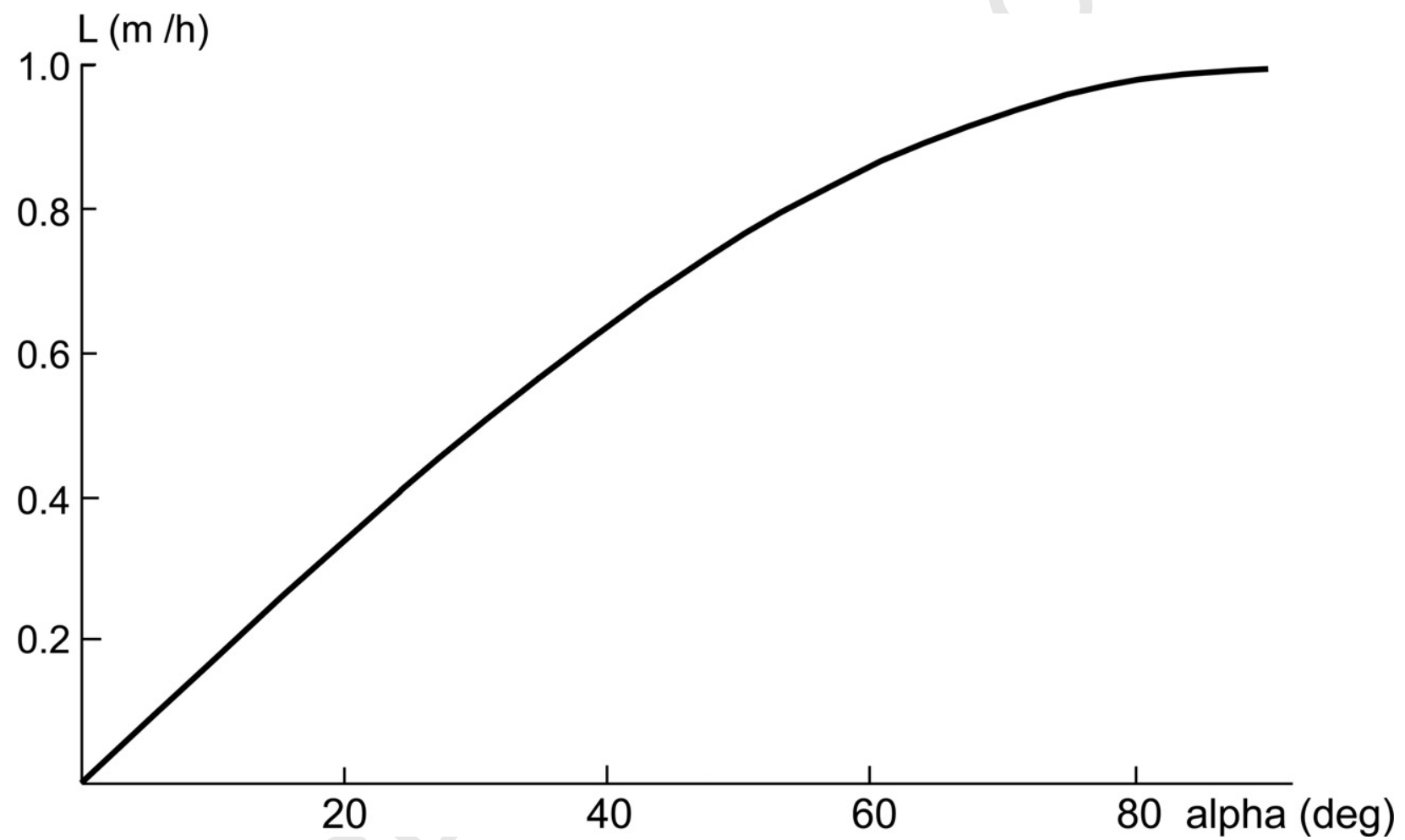

Fig 15 